CAMAR Working Paper Series

No $1 / 2010$

\title{
How does monetary policy respond to exchange rate movements? \\ New international evidence
}

Hilde C. Bjørnland and Jørn I. Halvorsen

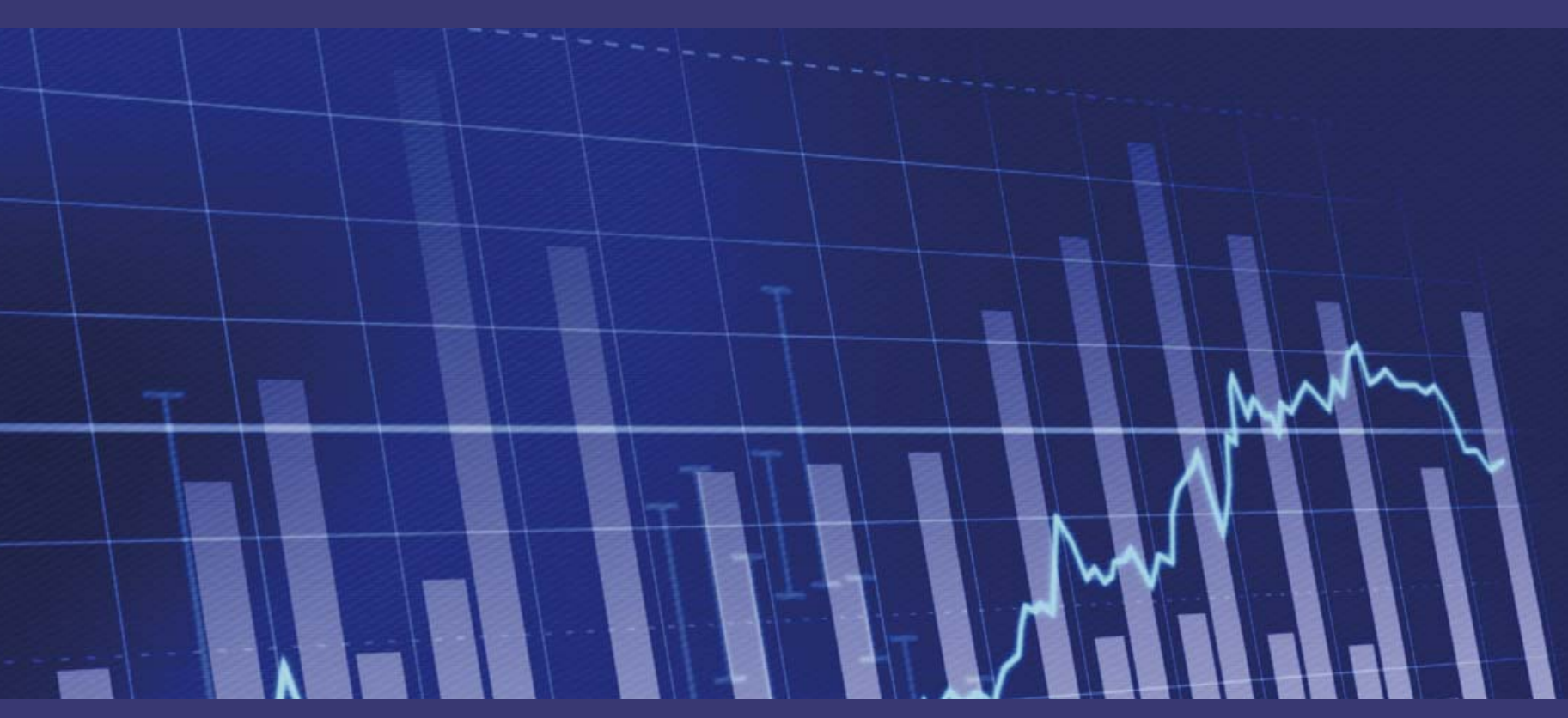

(c) Authors 2010.

This paper can be downloaded without charge from the CAMAR website http://www.bi.no/camar 


\title{
How does monetary policy respond to exchange rate movements? New international evidence *
}

\author{
Hilde C. Bjørnland ${ }^{\dagger}$ \\ Jørn I. Halvorsen \\ Norwegian School of Management \\ Norwegian School of Management \\ and \\ Norges Bank
}

November 4, 2010

\begin{abstract}
This paper analyzes how monetary policy has responded to exchange rate movements in six open economies, paying particular attention to the two-way interaction between monetary policy and the exchange rate. We address this issue using a structural VAR model that is identified using a combination of sign and short-term (zero) restrictions. Our suggested identification scheme allows for a simultaneous reaction between the interest rates and the exchange rate. Doing so we find that, while there is a instantaneous reaction in the exchange rate following a monetary policy shock in all countries, monetary policy responds on impact to an exchange rate shock in only four of the six countries. While this suggests that the exchange rate is not equally important in the interest rate setting in all countries, we find that accounting for a potential interaction is still crucial when identifying monetary policy shocks in open economies structural VARs.
\end{abstract}

JEL-codes: C32, E52, F31, F41.

Keywords: Exchange rate, monetary policy, SVAR, Bayesian estimation, sign restrictions.

*We thank Gernot Doppelhofer, Mardi Dungey, Renee A. Fry, Christian Kascha, Kai Leitemo, Francesco Ravazzolo, participants at the SOEGW 2008 conference in Toronto, the CFE 2008 conference in Neuchâtel, the MMF 2008 conference in London as well as seminar participants at the Norwegian School of Economics and Business Administration for their useful comments and suggestions. The authors thank the Norwegian Financial Market Fund under the Norwegian Research Council for financial support. Views expressed are those of the authors and do not necessarily reflect the views of Norges Bank.

${ }^{\dagger}$ Corresponding author: Department of Economics, Norwegian School of Management (BI), 0442 Oslo, Norway. Email. hilde.c.bjornland@bi.no 


\section{Introduction}

In 2001, John B. Taylor wrote: "An important and still unsettled issue for monetary policy in open economies is how much of an interest-rate reaction there should be to the exchange rate in a monetary regime of a flexible exchange rate, an inflation target, and a monetary policy rule." (Taylor (2001)).

Nine years on, the issue still remains unsettled. Yet, several times a year, the Board of an inflation-targeting central bank meets to analyze the development of a series of economic variables, including the exchange rate. For a small open economy, the exchange rate plays a crucial role in relation to monetary policy. It plays a significant part in the formulation of monetary policy (being an important influence on the overall level of demand and prices), and is itself also influenced by monetary policy. Understanding the role of the exchange rate in the transmission mechanism of monetary policy, as well as quantifying the appropriate interest rate reaction to exchange rate fluctuations, is therefore imperative for the implementation of an efficient monetary policy strategy.

This paper analyzes the interaction between monetary policy and the exchange rate in six open (inflation-targeting) countries, focusing in particular on how monetary policy has responded to exchange rate movements. We address this issue using a structural vector autoregressive (VAR) model that is identified using a combination of sign and shortrun (zero) restrictions which preserves the endogenous interaction between the interest rate and the exchange rate commonly observed in the market. The novel feature of our approach is that, instead of the conventional view of using a recursive Cholesky ordering for all of the variables, or the more recent view of relying on only pure sign restrictions, we combine short term (zero) restrictions and sign restrictions in an intuitive way. That is, we allow for a simultaneous reaction between the variables that are observed to respond intraday to news (the interest rate and the exchange rate), but maintain 
the short term (zero) restrictions for the traditional macroeconomic variables that are observed to respond with delay to economic shocks (output, inflation etc.). Identified in this way, we believe the VAR approach is likely to give very useful information about monetary policy and exchange rate dynamics in the open economy, that previous studies have been unable to recover.

Up to now, the standard approach for analyzing monetary policy responses has been to estimate interest rate rules like the simple Taylor rule. For the closed economies, Taylor rules are often estimated using a single equation framework that quantifies the actual interest rate response to observed changes in economic variables such as inflation and the output gap, see e.g. Taylor (1999). For open economies, the Taylor rule is frequently augmented to also include the exchange rate. However, the commonly observed simultaneity between the interest rate and the exchange rate implies that the policy rule needs to be estimated simultaneously with a reaction function for the exchange rate. In most cases this is not trivial, and parameters often end up being insignificant.

More recently, Lubik and Schorfheide (2007) and Dong (2008) have instead favored a multivariate approach when estimating policy rules in the open economy. Using Bayesian estimation techniques and dynamic stochastic general equilibrium (DSGE) models, they estimate whether monetary policy responds to exchange rate movements. In contrast to the single equation approaches, both find that the interest rate increases systematically in all countries following an exchange rate depreciation. However, the response is modest, although it varies somewhat between the different countries.

The focus of this paper will be to specify multivariate VARs to analyze policy reaction (operationalized through short-term interest rates) to shocks in the exchange rate. By investigating the impulse responses and variance decomposition of the policy instrument in response to the identified shocks, one can get an idea of how central banks use the instrument to reach their goals. While this is not the same as estimating interest rate rules, 
we believe that the information as to how the interest rates actually react to shocks to be equally interesting, and more to the point, in describing how central banks implement policy. Furthermore, the empirical results may be an important addition to the more theoretically driven structural model responses derived in Lubik and Schorfheide (2007) and Dong (2008), where the chosen exchange rate specification in the DSGE model influence the results. The paper therefore contributes with new empirical evidence, as well as providing a methodological contribution on how one can identify monetary policy and exchange rate shocks in the open economy structural VAR.

The analysis is applied to six open economies with floating exchange rates: Australia, Canada, New Zealand, Norway, Sweden and the UK. We find evidence of simultaneous reaction between monetary policy and the exchange rate. However, while there is a strong and persistent reaction in the exchange rate following a monetary policy shock in all countries, the degree of response in the interest rate following an exchange rate shock varied between the different countries. However, while this should suggest that the exchange rate may not be an important variable in the interest rate determination in all countries, accounting for this interaction is still very important when identifying monetary policy in open economies structural VARs.

The paper is organized as follows. Section 2 motivates and presents our suggested identification scheme that combines short term (zero) and sign restrictions to identify the shocks. In Section 3 we present the empirical results and discuss robustness. Section 4 concludes.

\section{The open economy structural VARs}

A major challenge when analyzing monetary policy in the open economy is how to identify the structural shocks when there is simultaneity between the interest rate and the 
exchange rate. Most of the traditional VAR studies of the open economies ignore this simultaneity, by placing recursive, contemporaneous restrictions on the interaction between monetary policy and the exchange rate. Typically, they either assume a lagged response in the systematic monetary policy setting to exchange rate news (see e.g. Eichenbaum and Evans (1995), Peersman and Smets (2003) and Lindé (2003)), or a lagged response in the exchange rate to monetary policy shocks (see e.g. Kim (2002) and Mojon and Peersman (2003)).

However, both restrictions are potentially wrong. The first as it prevents the policymaker from using all the current information when designing monetary policy. The restriction is also useless for the purpose of our study, which seeks to quantify this policy response. The second restriction is equally implausible, as it imposes strong restrictions on the flexibility of the exchange rate that is not supported in studies using high frequent data. ${ }^{1}$ As a consequence, these studies have reported many puzzles with regard to the effects of monetary policy on the exchange rate. ${ }^{2}$

The issue of identification has not gone unattended. In an early attempt to solve the puzzle, Cushman and Zha (1997) suggested that one should identify monetary policy shocks in a simultaneous environment, using a systems method of estimation. As a result, they found instant responses in the exchange rate. More recently, Bjørnland (2009) has addressed this issue exploring long run neutrality restrictions to identify the VAR. Doing so, she found instant overshooting in the exchange rate.

The above mentioned studies seek exact identification of the structural shocks (monetary policy shocks in particular). In an alternative approach, Faust and Rogers (2003)

\footnotetext{
${ }^{1}$ See for instance the event studies Bonser-Neal, Roley, and Sellon (1998), Zettelmeyer (2004) and Kearns and Manners (2006) among others.

${ }^{2}$ For instance, following a contractionary monetary policy shock, the exchange rate often depreciates, or if it appreciates, it does so for a prolonged period, thereby giving a hump-shaped response that violates uncovered interest parity (UIP). In the literature, the first phenomenon has been referred to as the exchange rate puzzle, whereas the second is termed delayed overshooting (or forward discount puzzle), see Cushman and Zha (1997).
} 
have used sign restrictions to test the implications of the short-run (zero) restrictions commonly applied. Using this framework, they find that traditional VARs may have produced a numerically important bias in the estimate of the degree of interdependence. By relaxing the zero restrictions, they find that the exchange rate instead appreciates on impact. However, their approach of relying of pure sign restriction can not identify the precise exchange rate responses to the monetary policy shocks, which could be immediate or delayed. To do so, one needs to apply additional restrictions, or, allow the sign restrictions imposed to be effective for a prolonged period, see e.g. Scholl and Uhlig $(2008) .^{3}$

An obstacle with the approach of relying on pure sign restrictions when identifying a structural VAR model, is that the identification scheme will be non-unique. This has been emphasized by Fry and Pagan (2007), which show that due to the weakness of information contained in the sign restrictions, there will be many impulse responses that can satisfy each sign restriction. When a series of impulse responses are compatible with a particular restriction, identification will not be exact. Canova and Paustian (2007) and Paustian (2007) have further shown that sign restrictions can only uniquely pin down the unconstrained impulse responses when the imposed restrictions are sufficiently numerous. Otherwise, the use of sign restrictions could lead to the identified shock being a hybrid of shocks, lacking clear economic interpretation.

In this paper, we suggest instead to combine sign and short-run (zero) restrictions to identify the VAR. By using sign restrictions, we allow some of the structural shocks to have immediate impact on the variables in the system. The use of zero restrictions, on the other hand, increases the information content of the identification procedure and thereby removes some of the problem of non-uniqueness associated with relying on pure

\footnotetext{
${ }^{3}$ Scholl and Uhlig (2008) impose sign restrictions for up to a year after the shocks, but find no evidence of instant overshooting. Similar restrictions are in place also in Farrant and Peersman (2006). However, they impose signs restrictions on all the variables of interest, thereby leaving no response open for testing.
} 
sign restrictions.

\subsection{Specification of the VAR model}

The choice of variables included in the VAR model is based on small open economies with a New-Keynesian framework, such as the one described in Svensson (2000) and Clarida, Gali, and Gertler (2001). Formally, the variables to be included consist of $X_{t}=$ $\left[\pi_{t}, y_{t}, i_{t}^{*}, i_{t}, r e_{t}\right]^{\prime}$, where $i_{t}^{*}$ is the foreign short-term nominal interest rate, $y_{t}$ is the log of real GDP, $\pi_{t}$, is the log of the price differential within a year, $i_{t}$ the short-term nominal interest rate, and $r e_{t}$ the log of the country's real exchange rate.

The five variables can be estimated jointly in the reduced form $\operatorname{VAR}(\mathrm{p})$, which in matrix form (ignoring any deterministic terms) can be expressed as

$$
B(L) X_{t}=e_{t}, \text { with } \Sigma_{e}=E\left(e_{t} e_{t}^{\prime}\right)
$$

$B(L)$ is here a $(5 x 5)$ matrix polynomial in the lag operator $L, B(L)=\sum_{i=0}^{p} A_{i} L^{i}$ with $A_{0}=I_{5} . e_{t}$ is the one step ahead prediction error which is assumed to be normally distributed with a positive semidefinite covariance matrix $\Sigma_{e}$. Given that $B(L)$ is invertible, the VAR model can also be written in terms of its moving average (MA) representation:

$$
X_{t}=C(L) e_{t}
$$

where $C(L)=B(L)^{-1}$.

Following common standard, we let the error term $e_{t}$ be linearly related to vector $\epsilon_{t}$ of orthogonal structural shocks normalized to have unit variance, $e_{t}=A \epsilon_{t}$. Inserting for 
this expression into (2) gives the MA representation in terms of the structural shocks.

$$
X_{t}=D(L) \epsilon_{t}, \text { where } D(L)=C(L) A \text { and } \epsilon_{t} \sim N\left(0, \operatorname{diag}\left(I_{5}\right)\right)
$$

Note, first, that the contemporaneous matrix $A$ is not unique since the covariance matrix of the residuals can lend itself to many different type of decompositions, e.g. $A A^{\prime}=\Sigma_{e}$ and $\tilde{A} \tilde{A}^{\prime}=\Sigma_{e}$. However, any two different decompositions must satisfy the fact (see Uhlig (2005)) that $A=\tilde{A} Q$, where $Q$ is an orthogonal matrix with property of (i) being mutually perpendicular, $\left\langle q_{i}, q_{j}>=0\right.$ for for $i, j=1,2, \ldots, 5$ where $i \neq j$, and (ii) of being orthonormal (unit length), $\left\|q_{i}\right\|=1$.

Given the focus of the paper, we restrict our attention to identifying the monetary policy shock $\left(\epsilon_{t}^{M P}\right)$ and the exchange rate shock $\left(\epsilon_{t}^{E S}\right)$. To do so, we partition the $A$ matrix into two blocks $A=\left[A^{\prime} A^{\prime \prime}\right]$. We let $A^{\prime}=\tilde{A} Q^{\prime}$ be a $(5 \times 3)$ matrix containing the immediate impact from the structural shocks we do not identify, while $A^{\prime \prime}=\tilde{A} Q^{\prime \prime}=\left[\mathbf{a}^{M P}, \mathbf{a}^{E S}\right]$ a (5x2) matrix containing immediate impact from the structural shocks we would like to identify.

\subsection{Identification of monetary policy and exchange rate shocks}

The focal point of this paper is to investigate how (systematic) monetary policy has responded to movements in the exchange rate. To answer such a question, we place no restrictions on how the domestic interest rate may respond to an exchange rate shock. Instead we impose the restriction that the exchange rate has to appreciate (fall) on impact following a contractionary monetary policy shock, which is consistent with results from event studies that measure instant responses, (again, see e.g. Bonser-Neal, Roley, and Sellon (1998), Zettelmeyer (2004) and Kearns and Manners (2006) among others.) Note, however, that the sign restriction used here is in place for one period only, allowing the 
exchange rate to move in any direction after that.

In addition to the sign restriction, we will impose additional zero restrictions on the matrix containing the immediate impacts from the structural shocks, $A^{\prime \prime}$. In particular, we impose the restriction that monetary policy shocks have a non-immediate impact on inflation, output and the foreign interest rate, which represents the conventional view that due to nominal rigidities, there is a slow process of pass through to macroeconomic variables (Christiano, Eichenbaum, and Evans (1999)). The zero restriction on the foreign interest rate should be trivial since it seems unlikely that the interest setting of a small open economy will have any impact on the foreign interest rate. Finally, we assume that an exchange rate shock affects output and inflation with a lag, due to incomplete pass through from exchange rates to macroeconomic variables. We also assume a zero response in the foreign interest rate following an exchange rate shock, due to small country assumptions. We denote this identification scheme by $A_{d e f a u l t}^{\prime \prime}$,

To analyze robustness of these results, we will do two stepwise changes. First, we relax the sign restriction on the exchange rate following the monetary policy shock, restricting instead nominal interest rates to increase on impact following a positive exchange rate shock (that depreciates the exchange rate). This builds directly on Taylor (2001), that found that the exchange rate is included in a monetary policy rule. However, even if the exchange rate is not included in the policy rule, an interest rate response could be the outcome of an indirect effect that the exchange rate has on future output and inflation. We denote this identification schemes by $A_{\text {robust }_{I}}^{\prime \prime}$.

Second, for the four small countries (Australia, New Zealand, Norway and Sweden) we also replace the zero restriction on the foreign interest rate with a sign restriction that allows foreign interest rates to fall on impact following a shock that depreciates the trade weighted exchange rate $\left(A_{\text {robust }_{I I}}^{\prime \prime}\right)$. While for Canada and the U.K. it is plausible to assume a zero response in the interest rate in the U.S. (the main trading parter to 
Canada and the UK) following an exchange rate shock, this may be more controversial for the four small countries included here. In particular, following an exchange rate shock, one might expect an inverse reaction in the interest rate for some of the countries in the trade-weighted foreign interest rate compared to the domestic country.

Our imposed restrictions for all the three identification schemes; $A_{\text {default }}^{\prime \prime}, A_{\text {robust }_{I}}^{\prime \prime}$, $A_{\text {robust }_{I I}}^{\prime \prime}$, can now be written as:

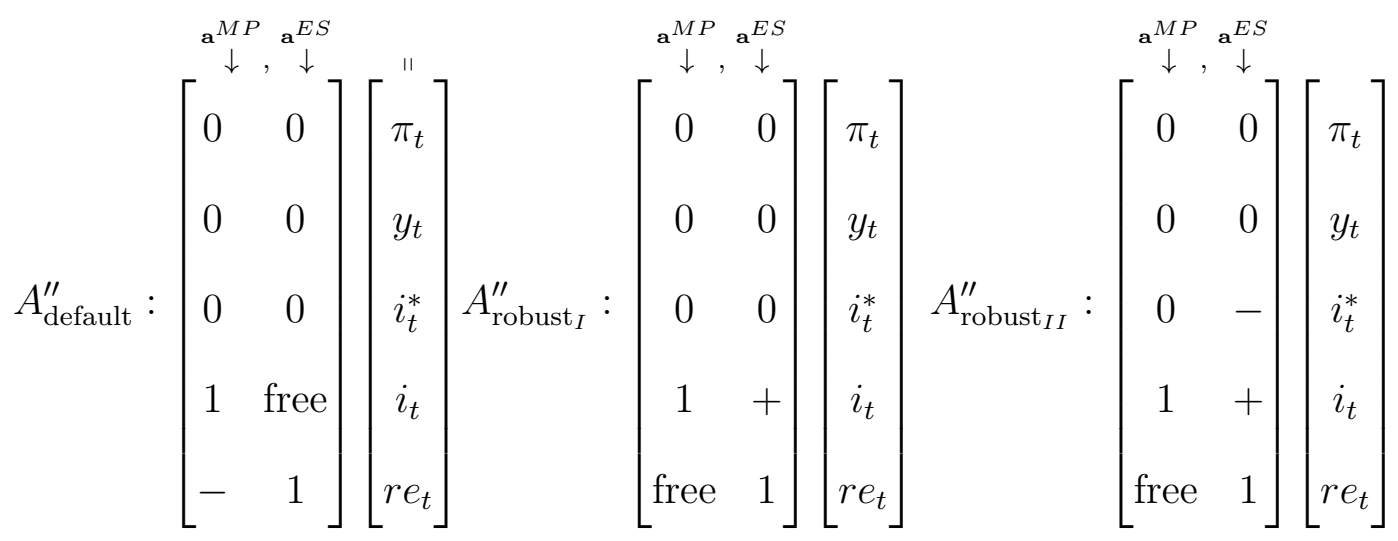

To estimate and analyze the impact of the two structural shocks on the variables in our VAR model, we employ a Bayesian numerical procedure quite similar to what is advocated in Uhlig (2005). The procedure is explained in more detail in Appendix A.

\section{Empirical results using the structural model}

The model is estimated for six countries: Australia, Canada, New Zealand, Norway, Sweden and the UK, using quarterly data from 1990Q1 to 2009Q4 (see Appendix A). Using an earlier starting period will make it hard to identify a stable monetary policy regime, as many countries were part of a fixed exchange rate regime until the late 1980s/early 1990s.

Consistent with most other related studies, the variables, with the exception of prices, are specified in levels. Rather than including prices, we include a measure of inflation, 
calculated as annual changes in the CPI. We have chosen to focus on annual inflation as it is a direct measure of the monetary policy target in the inflation-targeting countries. One may argue (Giordani (2004)) that with the theoretical model of Svensson (1997) as a datagenerating process, rather than including output in levels, one should either include the output gap in the VAR, or the output gap along with the trend level of output. However, as pointed out by Lindé (2003), a practical point that Giordani does not address is how to compute trend output (thereby also the output gap). To overcome this issue, we therefore instead follow Lindé (2003) and include a linear trend in the VAR along with output in levels. In that way we try to address this problem by modelling the trend implicit in the VAR. We choose four lags for all countries.

In a few cases impulse dummies, which take the value 1 in one quarter and 0 otherwise, were included, to take account of extreme outliers. In particular, three dummies were included for Sweden; 1992Q3, 1992Q4 and 1993Q1. ${ }^{4}$ For Norway, three impulse dummies were included for the periods; 1997Q1, 1997Q2 and 2002Q2. ${ }^{5}$ However, the main results are robust to our chosen specifications with regard to the trend, number of lags and dummies. $^{6}$

\subsection{The effects of monetary policy and exchange rate shocks}

Figures 1-6 show, for each of the six countries: Australia, Canada, New Zealand, Norway, Sweden and the UK respectively, the effect of the monetary policy shock (in the left column) on all five variables and the effect of an exchange rate shock (in the right column)

\footnotetext{
${ }^{4}$ The first two dummies capture an exceptionally high interest rate increase (500 percent) implemented by the Riksbank in order to defend the Swedish exchange rate, while the third reflects the subsequent floating of the Swedish krona.

${ }^{5}$ The dummies represent respectively a severe appreciation pressure against the Norwegian krone in the first quarter of 1997; subsequent depreciation in the second quarter, and finally a severe appreciation of the Norwegian krone in 2002 in excess of its fundamentals.

${ }^{6}$ In addition we have also tested robustness to the inclusion of additional exogenous variables (oil price) and sample stability. The results are robust and can be obtained at request.
} 
on the same variables, using our identification scheme $\left(A_{\text {default }}^{\prime}\right)$.

Figure 1: Australia: The response to monetary policy shocks and exchange rate shocks Impulse responses

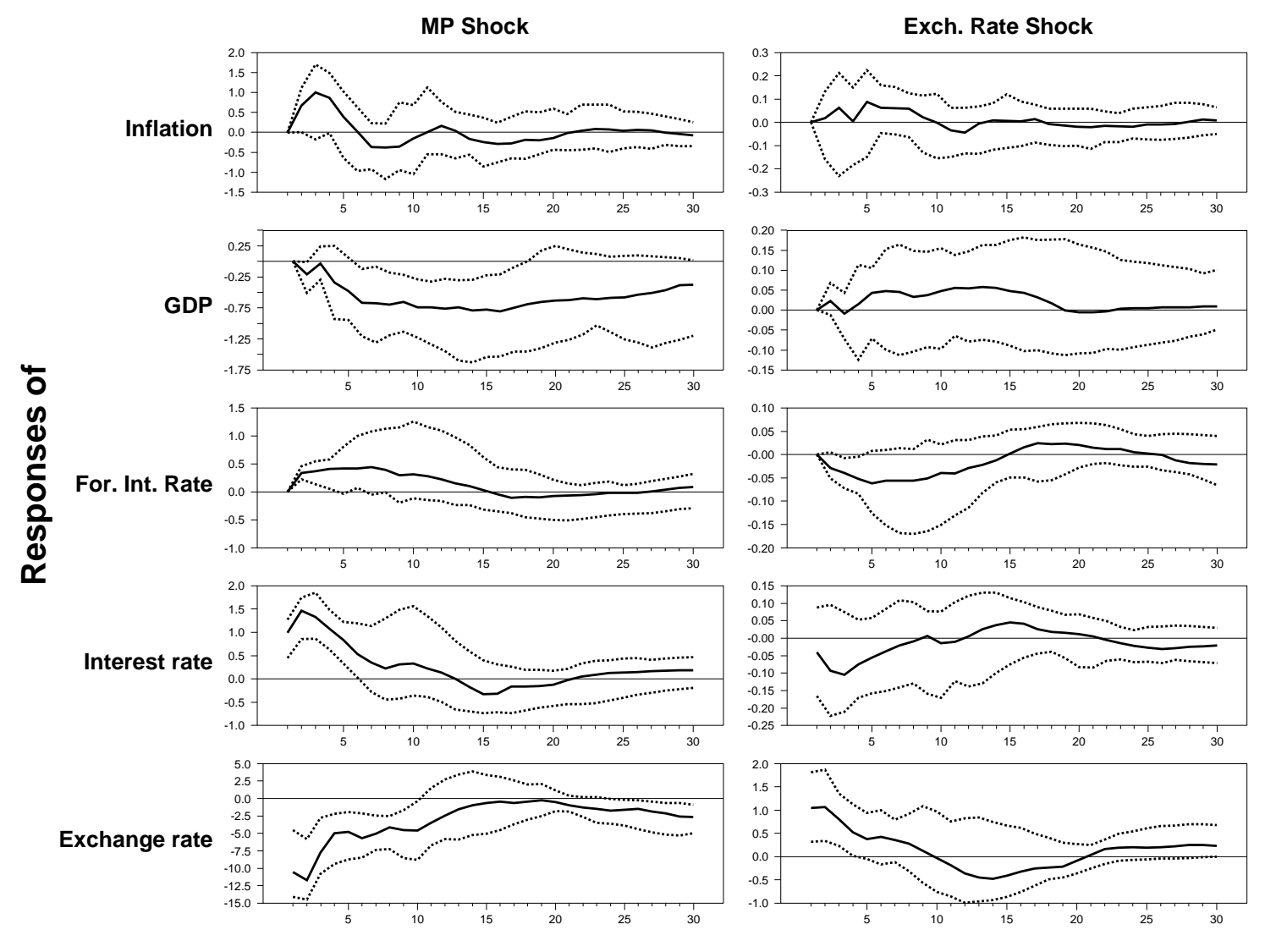

Focusing on the effect of the monetary policy shocks first, the figures suggest that a contractionary monetary policy shock, normalized to increase the interest rate with one percentage point initially, has the usual effects identified in other international studies. In particular, output falls gradually by up to 1.5 percent for 2-3 years before the effect essentially dies out. The effect on inflation is also eventually negative as expected and reaches its minimum after 3 years. However, for some countries (most notably in the UK) there is some evidence that consumer prices increase initially, commonly referred to as the price puzzle. ${ }^{7}$ Though, in most cases, this initial response is not significant.

\footnotetext{
${ }^{7}$ The puzzle has often been explained by a cost channel of the interest rate, where part of the increase
} 
Figure 2: Canada: The response to monetary policy shocks and exchange rate shocks

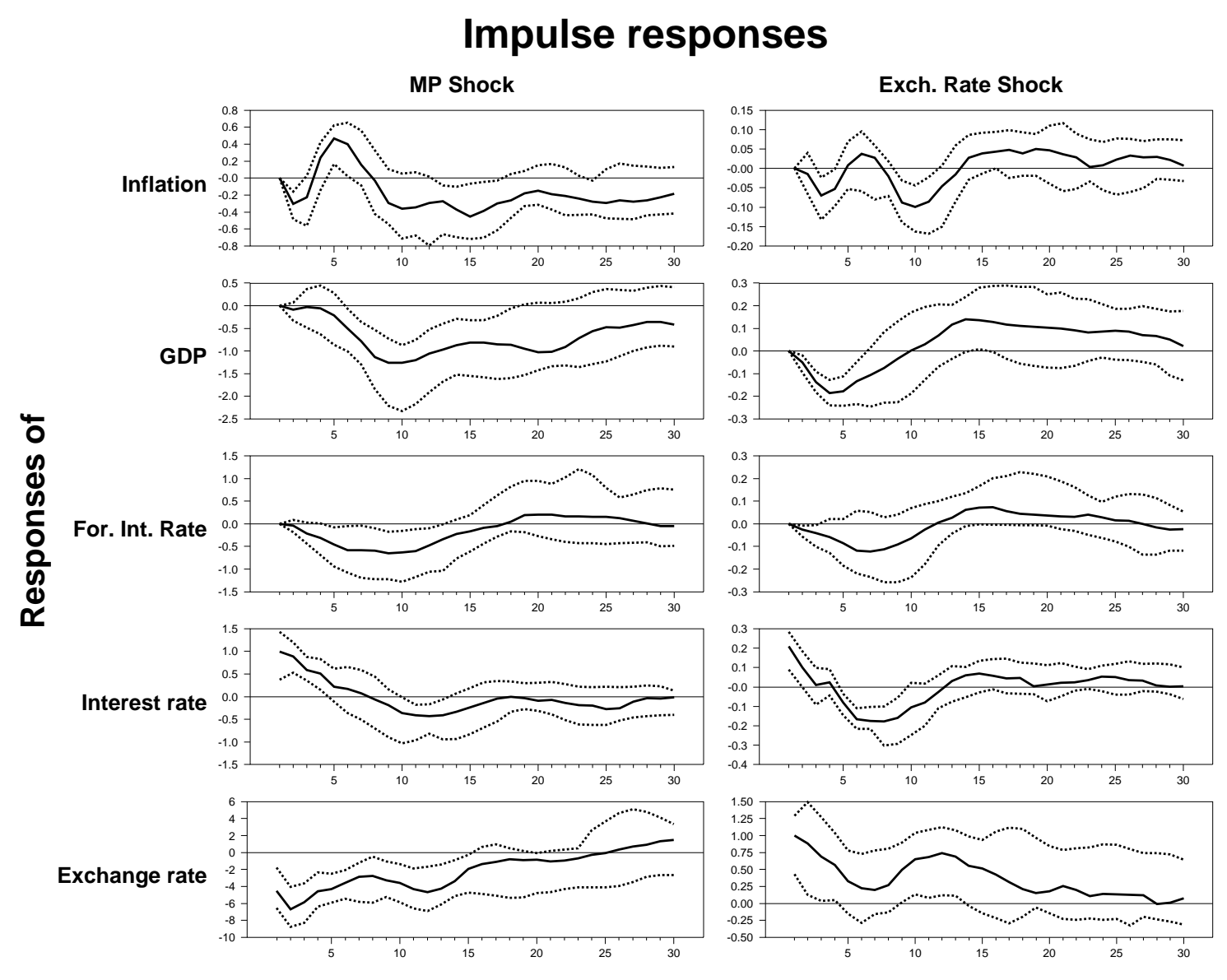

There is a high degree of interest-rate inertia in the model, in the sense that a monetary policy shock is only offset by a gradual reduction in the interest rate. The interest rate response is consistent with what has become known as good monetary policy conduct (see Woodford (2003)). In particular, interest-rate inertia is known to let the policymaker smooth the effects of policy over time by affecting private-sector expectations. Moreover, the reversal of the interest rate stance is consistent with the policymaker trying to offset the adverse effects of the initial policy deviation from the systematic part of policy.

Regarding the exchange rate, the figures show that in all countries the exchange rate appreciates on impact (as imposed by the sign restriction), but the effect is far from trivial.

in firms' borrowing costs is offset by an increase in prices (Ravenna and Walsh (2006) and Chowdhury, Hoffmann, and Schabert (2006)). 
Figure 3: New Zealand: The response to monetary policy shocks and exchange rate shocks

\section{Impulse responses}
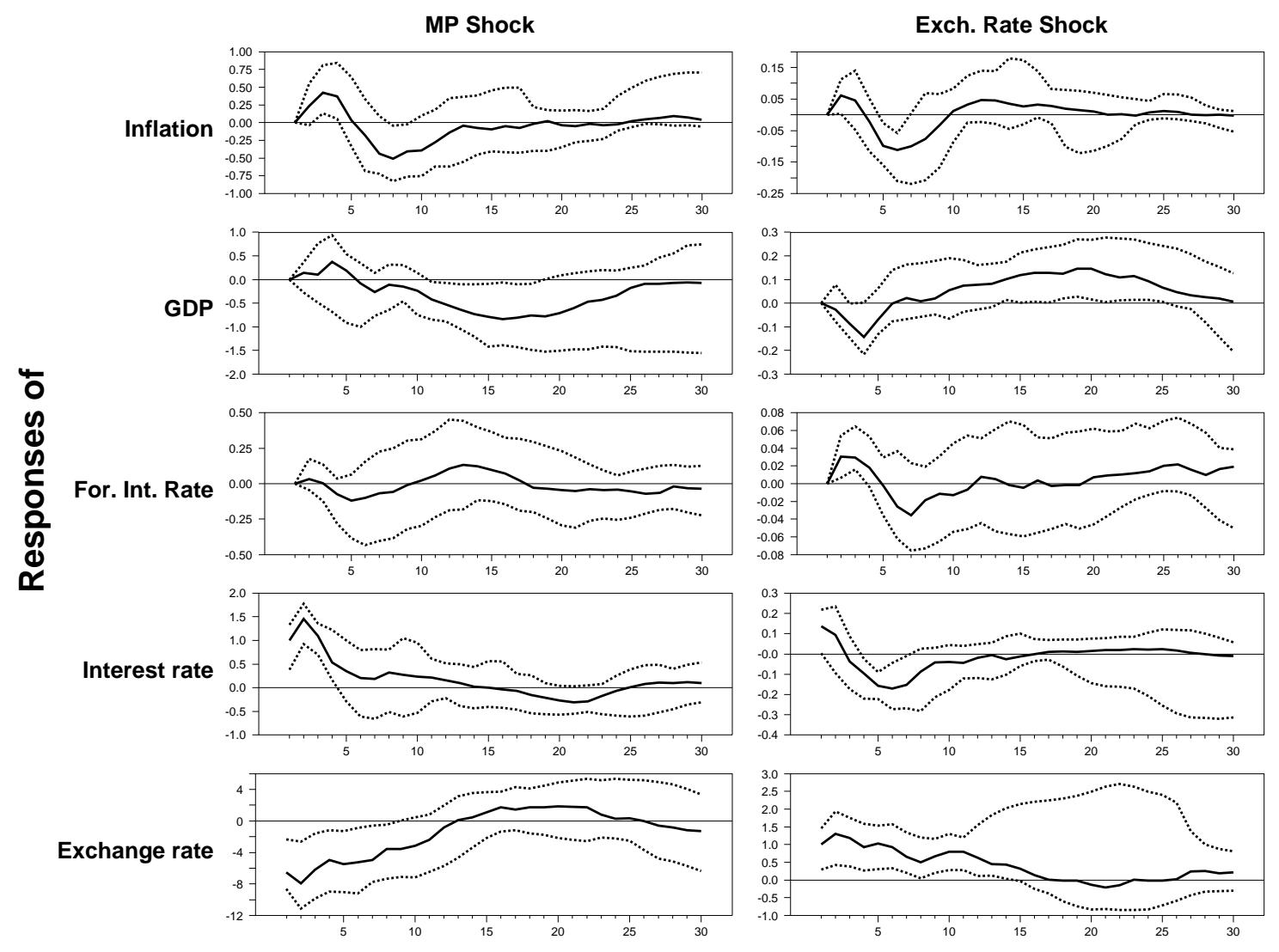

The median response indicates that for Australia and New Zealand, the exchange rate may fall by as much 8-10 percent initially, following (a normalized) one percentage point increase in the interest rate. For the other four countries, the exchange rate falls by 3-5 percent. Following the initial effect, the exchange rate thereafter gradually depreciates back to baseline in all countries, consistent with the Dornbusch overshooting hypothesis.

Having examined the response in the variables to a (unsystematic) monetary policy shock, we now ask, how does the instrument of monetary policy, i.e. the interest rate, react to an exchange rate shock? This is analyzed in the right column in the Figures 1-6. Recall that to obtain these results, we have not placed any restrictions on the response in the domestic interest rate. The results show that following an exchange rate shock 
Figure 4: Norway: The response to monetary policy shocks and exchange rate shocks

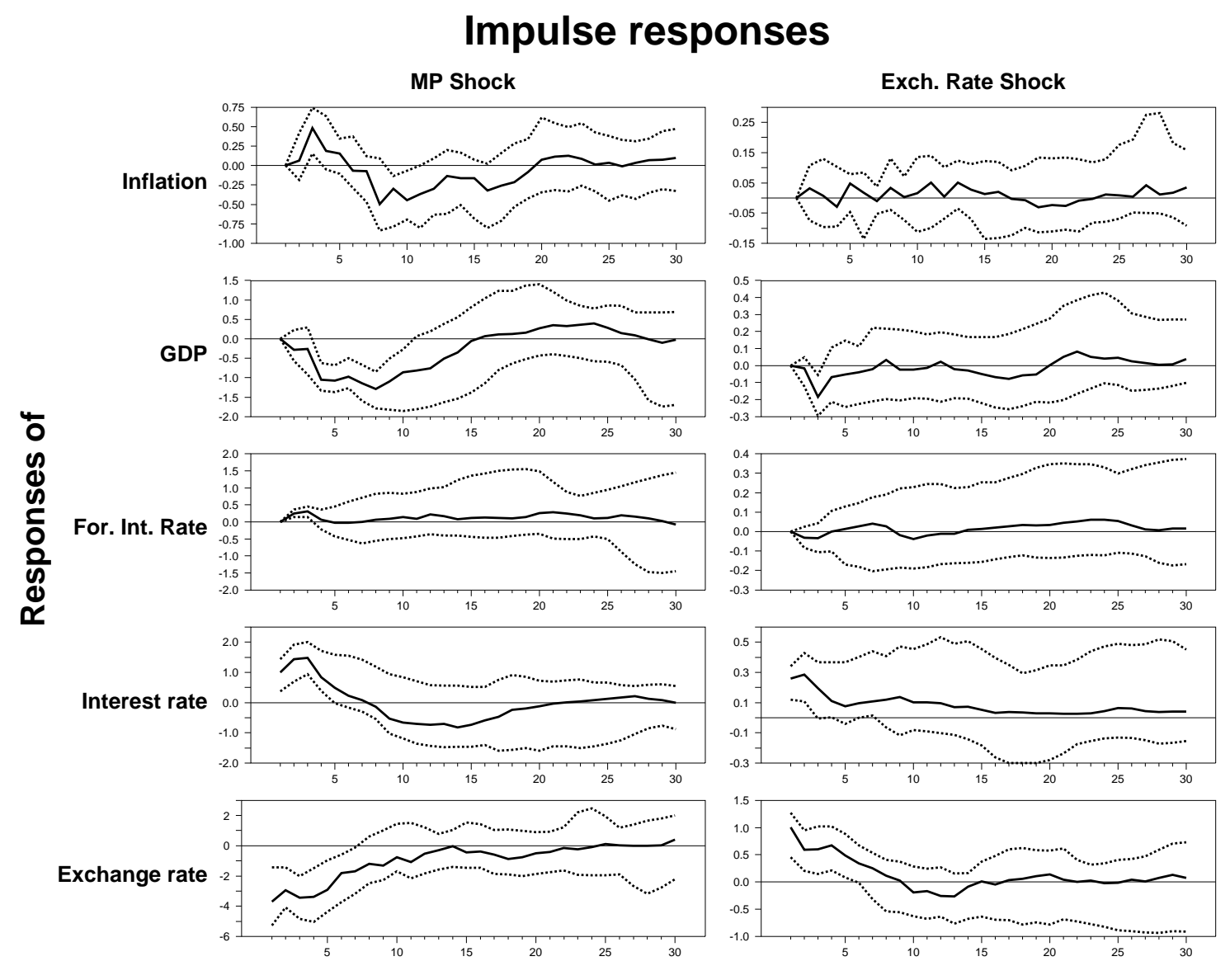

that depreciates (increase) the real exchange rate by one percent, the domestic interest rates increase by 10-30 basis points in all countries but Australia and the UK. For all countries but Norway and Sweden, the maximum interest rate response is immediate and then dies out within a year or so. For Norway and Sweden, the effect is delayed with one or two quarters before dying out. Hence, if the central banks respond to an exchange rate shock, they do so mainly within a year. Failing to account for this interaction will therefore probably bias all other results. For Australia and the UK, on the other hand, the interest rate response is insignificant (and for Australia, also negative). Hence, monetary policy does not respond to shocks in the exchange rate in these countries. Note also, that although the response in New Zealand and Norway is just significant, the bands are wide 
Figure 5: Sweden: The response to monetary policy shocks and exchange rate shocks

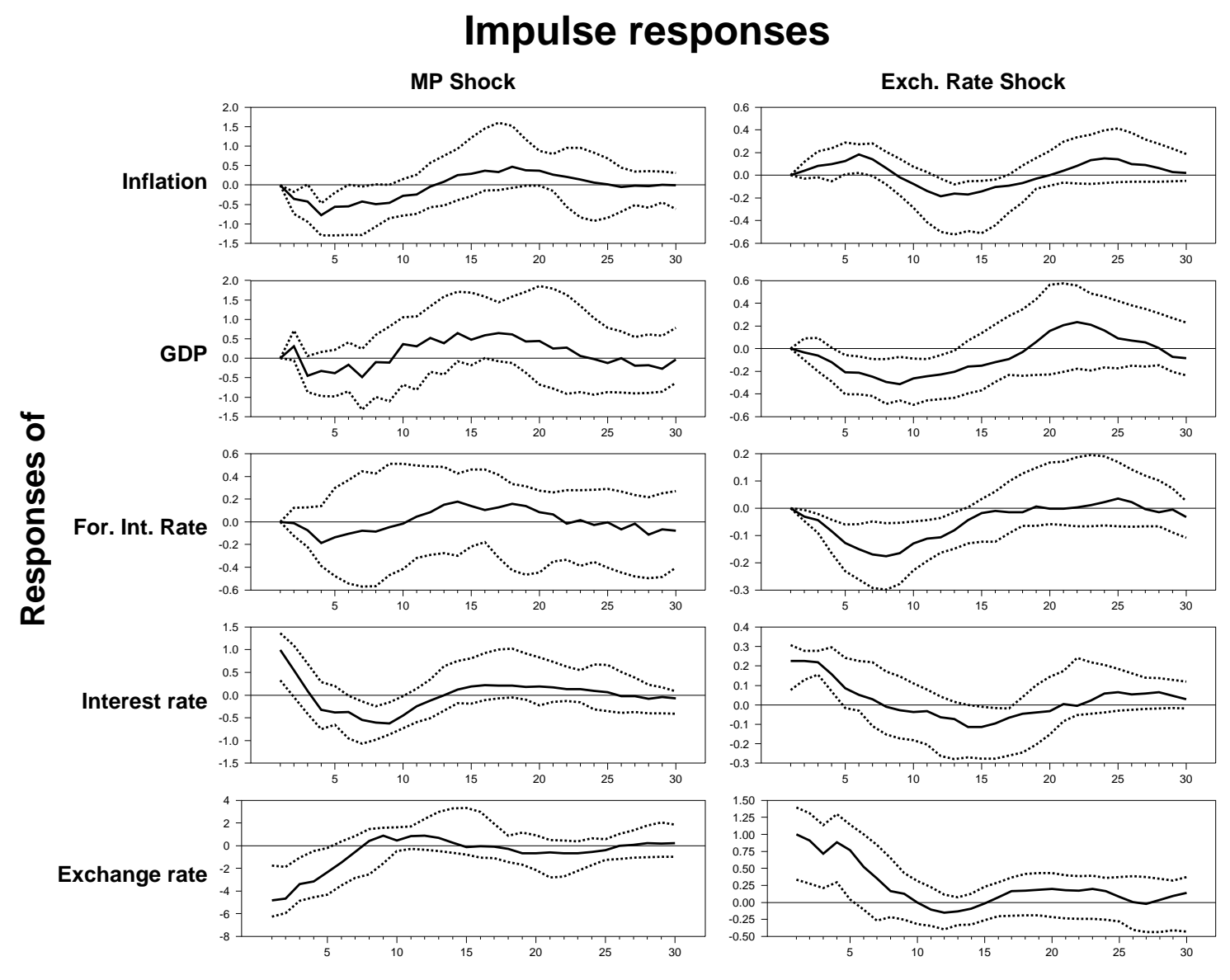

suggesting unprecise estimates.

Regarding the effect on the other variables, an exchange rate shock has a very small or insignificant effect on GDP. Hence, the countries that respond to an exchange rate shock may do so to smooth the impact of international relative price movements, rather than as a concern for the business cycles.

With the exception of Norway and Sweden, the foreign interest rate does not react significantly to an exchange rate shock at any horizon. For Norway and Sweden, though, there is a significant delayed negative effect on the foreign interest rate. The delayed reaction is due to the fact that we have imposed a zero restriction in the contemporaneous response in foreign interest rates to an exchange rate shock. While this is a plausible 
Figure 6: UK: The response to monetary policy shocks and exchange rate shocks

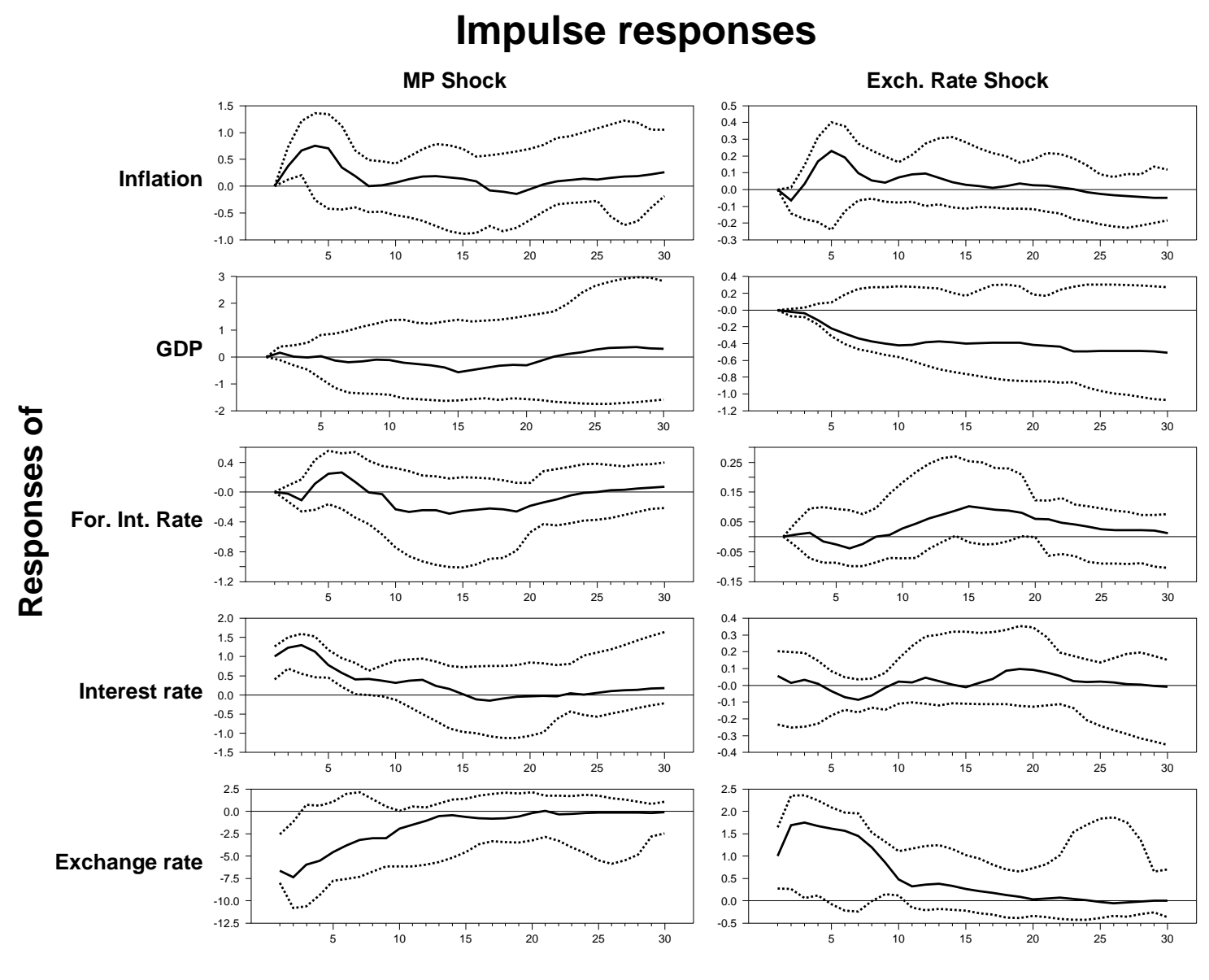

assumption for Canada and the UK (where the main trading parter is the U.S.), this may be more controversial for the smaller countries where we could expect an inverse reaction in the foreign interest rate. This will be examined in the robustness section below.

Variance decompositions also illustrate that the exchange rate plays an important role in the interest rate setting in four of the countries. For New Zealand, the exchange rate explains 10-15 percent of the initial interest rate variation. The contribution of the exchange rate increases to 30-35 percent for Canada, Norway and Sweden. However, the effect of the shocks thereafter quickly dies out, so that after one year, the exchange rate shocks explain 10-15 percent of the interest rate variation in all countries but Sweden, where the exchange rate explains close to 20 percent of the interest rate variations for two 
years. For Australia and the UK, the effect is negligible at all horizons, as the exchange rate explain less than 5 percent of the variation in the interest rate.

Table 1: Variance decomposition of the interest rate, 1,4 and 8 quarter horizon

\begin{tabular}{|c|c|c|c|}
\hline Shocks & Monetary policy shock & Exchange rate shock & Other shocks \\
\hline \multicolumn{4}{|l|}{ AUSTRALIA } \\
\hline 1-step & 0.37 & 0.04 & 0.59 \\
\hline 4-steps & 0.35 & 0.05 & 0.59 \\
\hline 8-steps & 0.28 & 0.05 & 0.67 \\
\hline \multicolumn{4}{|l|}{ CANADA } \\
\hline 1-step & 0.30 & 0.37 & 0.32 \\
\hline 4-steps & 0.22 & 0.16 & 0.62 \\
\hline 8-steps & 0.10 & 0.19 & 0.71 \\
\hline \multicolumn{4}{|l|}{ NEW ZEALAND } \\
\hline 1-step & 0.38 & 0.13 & 0.48 \\
\hline 4-steps & 0.32 & 0.09 & 0.58 \\
\hline 8-steps & 0.16 & 0.19 & 0.65 \\
\hline \multicolumn{4}{|l|}{ NORWAY } \\
\hline 1-step & 0.33 & 0.36 & 0.32 \\
\hline 4-steps & 0.40 & 0.18 & 0.42 \\
\hline 8-steps & 0.26 & 0.12 & 0.62 \\
\hline \multicolumn{4}{|l|}{ SWEDEN } \\
\hline 1-step & 0.32 & 0.32 & 0.36 \\
\hline 4-steps & 0.13 & 0.27 & 0.61 \\
\hline 8-steps & 0.16 & 0.17 & 0.67 \\
\hline \multicolumn{4}{|l|}{ UNITED KINGDOM } \\
\hline 1-step & 0.37 & 0.00 & 0.63 \\
\hline 4-steps & 0.24 & 0.00 & 0.75 \\
\hline 8-steps & 0.12 & 0.02 & 0.86 \\
\hline
\end{tabular}

Are these results plausible? Much of the theoretical research to date indicates that monetary policy rules that react directly to the exchange rate (in addition to inflation and output) do not work much better in stabilizing inflation and real output than policy rules that do not react to the exchange rate (see Taylor (2001) and the references stated therein). ${ }^{8}$ However, Taylor (2001) also points out that although there may be no evidence

\footnotetext{
${ }^{8}$ For instance, normative studies like Ball (1999) finds that although a depreciation of the exchange rate of 1 percent would call for an immediate interest rate response of 37 basis points, the effect would
} 
that the central bank follows a policy rule with a direct exchange rate effect, theory still suggests that there may be strong indirect effects of exchange rates on interest rates. This indirect effect is due to inertia in the monetary transmission mechanism which under rational expectation implies that changes in the real exchange rate will have an impact on future expectations of real output and inflation and as such having an impact on a monetary policy rule. Consistent with this, some inflation-targeting central banks like Sveriges Riksbank have argued that they specifically look at the exchange rate to assess to what extent it will impact on import prices and hence the inflation forecast. ${ }^{9}$

Hence, central banks may want to respond to real exchange rate movements in order to smooth international relative price fluctuations that could affect their international competitiveness and have an effect on aggregate demand for domestic goods, which is consistent with what we found here. This is also the inherent feature of the recent work by Lubik and Schorfheide (2007), which using a DSGE model report that in two of the four countries they examine (Canada and the UK), do the central banks include the exchange rate in their policy rules. Using a similar model, but allowing the exchange rate to be endogenously determined, Dong (2008) also report that the Reserve Bank of Australia respond to exchange rate movements.

However, while we also find that the Bank of Canada pay close attention to real exchange rate movements, we find little evidence that the Central Banks in Australia and the UK incorporate exchange rate movements into their policy rules. Instead, we find more responses in New Zealand, Norway and Sweden. Information available in speeches or publications from the Reserve Bank of Australia or the Bank of England, do not indicate

be partially offset by 15 basis points the period after. Similar responses are also suggested in Svensson (2000), but there the response is totally offset the next period.

${ }^{9}$ Heikensten (1998) writes (p.1): In this context I should like to elaborate on the Riksbank's appraisal of the Swedish krona... The Riksbank does not target the krona's exchange rate. But as one of the factors behind inflation, the exchange rate is important for monetary policy in a flexible exchange rate regime. A considerable period with a weak exchange rate might lead to a forecast rate of inflation that exceeds the target, in which case the Riksbank has to respond in order to meet this target. 
that they pay any particular attention to exchange rate movements when deciding on the appropriate monetary policy stance. ${ }^{10}$

In contrast, New Zealand has targeted the exchange rate directly in periods, by among others developing a monetary condition index (MCI) that encompasses both interest rate and exchange rate information as a more comprehensive indicator of the monetary stance. In particular, during the MCI period (1997-1999 in particular), the Reserve Bank of New Zealand let exchange rate depreciation result in automatic interest rate increases. This allowed interest rate increases at the onset of the Asian crisis in 1997/98, although economic conditions may have suggested differently (see Svensson (2001)). The MCI index has now been abandoned.

Bank of Canada has also developed a MCI in this period. However, the MCI has never been targeted directly, but has been used as a guide in monetary policy. Nevertheless, to check robustness to the MCI periods, we include dummies that allow for a deviation in policy in the periods when the Reserve Banks may have used a MCI (mid 1997 to March 1999). The results are robust to the MCI periods.

\subsection{Robustness to alternative restrictions}

Now we reverse the restrictions and identify the SVAR by assuming a positive sign on the impact response of the interest rate following an exchange rate shock, while leaving the exchange rate unrestricted to monetary policy shocks $\left(A_{\text {robust }_{I}}^{\prime}\right)$. Hence, this is a test for exchange rate overshooting.

Figures 7-12 in Appendix B display the response in the interest rate and the exchange rate only. The left column displays the effect of a monetary policy shock while the right

\footnotetext{
${ }^{10}$ Because Australia is commodity export dependent, but doesn't have any influence on either the currency of contracts or the world price (wheat, coal, iron ore), exchange rate shocks are most likely seen as being exogenously generated. Also, relative to rest of world's currencies, the exchange rate is quite volatile. This is likely to be partly due to it being the 4th most traded currency in the world.
} 
column displays the effect of an exchange rate shock. For all countries, the assumption of exchange rate overshooting is maintained. As found above, the maximum effect is felt initially, or at most, delayed by one quarter. This seems to be a robust feature of the data, as indicated by the $16-84$ percentiles error band around the median responses. In particular, we find no evidence of delay overshooting that has often been found in open economy VAR applications identified using recursive restrictions. Instead, our results are consistent with findings in Bjørnland (2009) and Cushman and Zha (1997), using either long-run (neutrality) restrictions or a structural approach to identify the VARs. The results are also in line with Faust and Rogers (2003) which, using sign restrictions only, could not rule out that there was an early peak in the exchange rate following a monetary policy shock. However, whereas they could not determine whether the maximum response was immediate or delayed, our results suggest the maximum response to be within a quarter.

Regarding the response in the interest rate (which we now force to respond positively initially) following an exchange rate shock, the conclusion with regard to the magnitude of responses from above holds. In particular, monetary policy in Australia and the UK do not respond by much, while for the other countries, the response is more substantial, 20-40 basis points following a shock that depreciates the exchange rate with one percent.

Finally, we also replace the zero restriction on the foreign interest rate with a sign restriction that allows foreign interest rates to fall on impact following a shock that depreciates the trade weighted exchange rate $\left(A_{\text {robust }_{I I}}^{\prime}\right)$. This is reported in Figures 13-16 in the appendix for the four small countries Australia, New Zealand, Norway and Sweden respectively. Generally, though, they support the conclusion from above. Relaxing the zero restriction on the foreign interest rate following an exchange rate shock do not alter the results very much.

To sum up. We have found evidence of simultaneous reaction between monetary 
policy and the exchange rate. However, while there is a strong and persistent reaction in the exchange rate following a monetary policy shock in all countries, the degree of response in the interest rate following an exchange rate shock varied between the different countries. However, while this should suggest that the exchange rate may not be an important variable in the interest rate determination in all countries, accounting for this interaction may still be important when identifying monetary policy in open economies. In particular, since most of the response is immediate, VAR studies that assume a lagged response in (the systematic) monetary policy setting to exchange rate news would most likely underestimate the monetary policy responses, as well as underestimate the role of the exchange rate in the the monetary policy transmission. This issue is explored further in the next section.

\subsection{Structural model versus a recursive Cholesky decomposition}

If monetary policy reacts immediately to exchange rate shocks and the exchange rate reacts on impact to monetary policy shock, then one would expect the interaction between interest rates and exchange rates to be important when identifying the various shocks. Below we examine the implications of our default identification scheme versus a traditional recursive Cholesky decomposition where we restrict the interest rate from responding to an exchange rate shock on impact. The results are summarized here, while the Figures are displayed in Appendix B. ${ }^{11}$

Starting with the effects of a monetary policy shock. The figure demonstrates that when monetary policy is identified using the traditional recursive Cholesky identification,

\footnotetext{
${ }^{11}$ Note that the solid line in the figures is the impulse responses found using the Cholesky decomposition with the exchange rate now ordered below the interest rate, while the dotted line is the median response following our suggested identification scheme. Again, for ease of exposition, the effect of the monetary policy shock (left column) is normalized to increase the interest rate by one percentage point initially, while the exchange rate shock (right column) is normalized to increase (depreciate) the exchange rate by one percent initially.
} 
there is virtually no exchange rate response to a monetary policy shock, with the exception of Australia and the UK, where both identifications schemes imply instant overshooting as in our structural model. This is very reassuring, as Australia and the UK were the only countries where the interest rate responded insignificantly to an exchange rate shock using our identification scheme. Hence, imposing zero response as the Cholesky restriction should make little difference.

Finally, note also that when the Cholesky identification is used, the effect of the monetary policy shock on the remaining variables will also be underestimated, suggesting less of an inflation and output response relative to the median response found using the our suggested restrictions. This seems to be the case for all countries. Hence, accounting for an interaction between monetary policy and the exchange rate is imperative not only for estimating the systematic response in the interest rate to exchange rate shocks, but also for establishing the role of the exchange rate in the monetary policy transmission.

Turning to the effect of the exchange rate shock. The figures suggest that when the recursive Cholesky identification is used, the interest rate does not respond to an exchange rate shock, even after a year. Hence, whereas our suggested restrictions has uncovered a clear interaction between the interest rate and the exchange rate, the conventional Cholesky identification would fail to recover any simultaneity between the interest rate and the exchange rate. This is important, as many researchers would argue that by restricting monetary policy from responding by one period only, one can still allow monetary policy to react to the exchange rate, but with a lag. However, as suggested from the figures above, the policy reaction will in most cases be severely underestimated. 


\section{Conclusions}

Empirical evidence using intraday data has shown that exchange rates react immediately to news, including news about monetary policy. If monetary policy also reacts quickly to surprise changes in the exchange rate, one would expect the interaction between interest rates and exchange rates to be important in applied analysis of monetary policy.

This paper has demonstrated that monetary policy and exchange rate interaction matter. By estimating VAR models that are identified using a combination of sign and short-term (zero) restrictions, we have analyzed how monetary policy has responded to exchange rate movements in six open economies. Our suggested identification scheme preserves the contemporaneous interaction between the interest rate and the exchange rate, without extensively deviating from the established literature of identifying a monetary policy shock as an exogenous shock to an interest rate reaction function.

The novel feature of such an approach is that, instead of the conventional view of using a recursive Cholesky ordering for all of the variables, or the more recent view of relying on only pure sign restrictions, we combine the two approaches in an intuitive way. That is, we allow for a simultaneous reaction between the variables that are observed to respond intraday to news (the interest rate and the exchange rate), but maintain the zero restrictions for the traditional macroeconomic variables that are observed to respond with delay (output, inflation etc.) to economic shocks.

Doing so, we find strong interaction between monetary policy and exchange rate variation in all countries but Australia and the UK. In particular, an exchange rate shock that depreciates the exchange rate by one percent, increases the interest rate on impact (within a quarter) by 10-30 basis points. However, the effect dies quickly out and for Australia and the UK, it is not ever significant. However, we find the impact of monetary policy shocks on exchange rates to be non-trivial and consistent with Dornbusch overshooting 
in all countries. In particular, a contractionary monetary policy shock that increases the interest rate by one percentage point, appreciates the exchange rate on impact by 3-10 percent. The exchange rate thereafter gradually depreciates back to baseline, broadly consistent with UIP. These results are in contrast to what has been found previously in the literature using recursive restrictions, or, pure sign restrictions, to identify the structural VARs.

\section{References}

BAll, L. (1999): "Policy Rules for Open Economies," in Monetary Policy Rules, ed. by john B. Taylor, pp. 127-144. University of Chicago Press.

BJøRnland, H. C. (2009): "Monetary policy and exchange rate overshooting: Dornbusch was right after all," Journal of International Economics, 79, 64-77.

Bonser-Neal, C., V. Roley, And G. Sellon (1998): "Monetary Policy Actions, Intervention, and Exchange Rates: A Reexamination of the Empirical Relationships Using Federal Funds Rate Target Data," Journal of Business, 71, 147-177.

Canova, F., and M. Paustian (2007): "Measurement with Some Theory: Using Sign Restrictions to Evaluate Business Cycle Models," Manuscript, Universitat Pompeu Fabra.

Chowdhury, I., M. Hoffmann, and A. Schabert (2006): "Inflation dynamics and the cost channel of monetary transmission," European Economic Review, 50, 995-1016.

Christiano, L. J., M. Eichenbaum, and C. L. Evans (1999): "Monetary Policy Shocks: What Have We Learned and to What End?," in Handbook of Macroeconomics. Volume 1A, ed. by J. B. Taylor, and M. Woodford, pp. 65-148. Elsevier Science. 
Clarida, R., J. Gali, and M. Gertler (2001): "Optimal Monetary Policy in Open Versus Closed Economies: An Integrated Approach," American Economic Review Papers and Proceeding, 91, 248-252.

Cushman, D. O., and T. Zha (1997): "Identifying monetary policy in a small open economy under flexible exchange rates," Journal of Monetary Economics, 39, 433-448.

Dong, W. (2008): "Do Central Banks Respond to Exchange Rate Movements?Some New Evidence from Structural Estimation," Mimeo, Bank of Canada.

Eichenbaum, M., And C. L. Evans (1995): "Some Empirical Evidence on the Effects of Shocks to Monetary Policy on ExchangeRates," The Quarterly Journal of Economics, pp. $975-1009$.

Farrant, K., And G. Peersman (2006): "Is the Exchange Rate a Shock Absorber or a Source of Shocks? New Empirical Evidence," Journal of Money, Credit and Banking, 38, 939-961.

FAust, J., AND J. Rogers (2003): "Monetary policy's role in exchange rate behaviour," Journal of Monetary Economics, 50, 1403-1424.

Fry, R., ANd A. Pagan (2007): "Some Issues in Using Sign Restrictions for Identifying Structural VARs," NCER Working Paper 14.

Giordani, P. (2004): "An alternative explanation of the price puzzle," Journal of Monetary Economics, 51, 1271-1296.

Halvorsen, J. I. (2009): "Essays on Economic Fluctuations in an Open Economy.," Ph.D. thesis, Norwegian School of Economics and Business Administration (NHH).

Heikensten, L. (1998): "Inflation and monetary policy," Sveriges Riksbank Deputy Governor Speech to Swedish Shareholders Association. 
Kearns, J., And P. Manners (2006): “The Impact of Monetary Policy on the Exchange Rate: A Study Using Intraday Data," International Journal of Central Banking, 2, 157 183.

KIM, S. (2002): "Exchange rate stabilization in the ERM: identifying European monetary policy reactions," Journal of International Money and Finance, 21, 413-434.

Lindé, J. (2003): "Monetary Policy Shocks and Business Cycle Fluctuations in a Small Open Economy: Sweden 1986-2002," Sveriges Riksbank Working Paper Series No.153.

Lubik, T. A., And F. Schorfheide (2007): "Do central banks respond to exchange rate movements? A structural investigation," Journal of Monetary Economics, 54, 1069-1087.

Mojon, B., and G. Peersman (2003): "A VAR description of the effects of monetary policy in the individual countries of the Euro area," in Monetary Policy Transmission in the Euro Area, Part 1, ed. by I. Angeloni, A. Kashyap, and B. Mojon, pp. 56-74. Cambridge University Press.

Paustian, M. (2007): "Assessing Sign Restrictions," The B.E. Journal of Macroeconomics, 7(1, Article 23).

Peersman, G., and F. Smets (2003): "The monetary transmission mechanism in the euro area: more evidence from VAR analysis," in Monetary Policy Transmission in the Euro Area, Part 1, ed. by A. K. I. Angeloni, and B. Mojon, pp. 36-55. Cambridge University Press.

Ravenna, F., And C. E. Walsh (2006): "Optimal monetary policy with the cost channel," Journal of Monetary Economics, 53, 199-216. 
Scholl, A., And H. Uhlig (2008): "New Evidence on the Puzzles. Results from an Agnostic Identification on Monetary Policy and Exchange Rates," Journal of International Economics, 76, 1-13.

Svensson, L. (1997): "Inflation Forecast Targeting: Implementing and Monitoring Inflation Targets," European Economic Review, 41, 1111-1146.

(2000): "Open-economy inflation targeting," Journal of International Economics, 50, 155-183.

- (2001): "Independent Review of the Operation of Monetary Policy in New Zealand: Report to the Minister of Finance," Mimeo, Stockholm University.

TAYlor, J. B. (1999): Monetary Policy Rules. University of Chicago Press.

(2001): "The Role of the Exchange Rate in Monetary-Policy Rules," American Economic Review, 91, 263-267.

Uhlig, H. (2005): "What are the Effects of Monetary Policy on Output? Results from an Agnostic Identification Procedure," Journal of Monetary Economics, 52, 381-419.

Woodford, M. (2003): "Optimal Interest-Rate Smoothing," Review of Economic Studies, 70, 861-886.

Zettelmeyer, J. (2004): "The impact of monetary policy on the exchange rate: evidence from three small open economies," Journal of Monetary Economics, 51, 635-652. 


\section{Appendix A}

\section{$5.1 \quad$ Data sources}

All data are taken from the OECD database, except the Fed Funds rate that is taken from Eco Win. GDP and inflation are seasonally adjusted (s.a.) by the official sources, the remaining series are unadjusted. The following data series are used:

$\left(\pi_{t}\right)$ Inflation, measured as annual changes in the consumer price index (CPI).

$\left(y_{t}\right)$ Log real GDP, deflated by the official sources.

$\left(r e_{t}\right)$ [CCRETT01.IXOB.Q] Log of the real effective exchange rate, measured against a basket of trading partners. The exchange rate is specified so that an increase implies depreciation.

$\left(i_{t}\right)$ [IR3TBB01.ST.Q] Three month domestic interest rate.

$\left(i_{t}^{*}\right)$ Trade-weighted foreign interest rate. For Canada and the UK, the foreign interest rate is represented by the Federal Funds rate, as the US comprises more than 80 percent of the foreign trade weight. For Australia, New Zealand, Norway and Sweden, the foreign interest is an weighted average of the interest rate in the major trading partners, source: Reserve Bank of Australia (http://www.rba.gov.au/), Reserve Bank of New Zealand (http://www.rbnz.govt.nz/), Norges Bank (http://www.norges-bank.no) and Sveriges Riksbank ( http://www.riksbank.com/) respectively. 


\subsection{Technical execution of identification, estimation and infer- ence}

Given the restrictions from out three identification schemes, we would like to carry out estimation and inference (i.e. impulse responses and variance decompositions) of the impact the two structural shocks have on the variables in our VAR model. We approach this issue employing a Bayesian numerical procedure quite similar to what is advocated in Uhlig (2005). The procedure can be separated into two parts. In the first part, $n 1$ draws are taken from the reduced form coefficients from our VAR posterior. ${ }^{12}$ Conditioned on each draw, the second part makes $n 2$ candidate draws for the two structural shocks included in the $A^{\prime \prime}$ matrix in which the draws that are satisfying our sign restrictions are being kept. Based on the accepted draws from these procedure, error bands for our statistical inference are calculated.

In the second part, we have augmented the procedure discussed in Uhlig (2005). First, since we are interested in identifying two types of structural shocks, $A^{\prime \prime}$ must consists of a impulse matrix (not a impulse vector) that form two columns of A. Second, when searching for candidate draws for our $A^{\prime \prime}$ matrix, the search must be restricted such that the zero restrictions that we have imposed on our $A^{\prime \prime}$ matrix from $A_{\text {default }}^{\prime \prime}, A_{\text {robust }_{I}}^{\prime \prime}$ and $A_{\text {robust }_{I I}}^{\prime \prime}$ are kept. As shown in Halvorsen (2009), it turns out that we can address both these issues using a Gram-Schmidt procedure based on input in the form of restricted draws.

Technically, we can describe our process as follows: We start by fixing $\tilde{A}$, by selecting $\tilde{A}=A^{\text {chol }}$ (i.e. the lower triangular matrix of the Cholesky decomposition). Further, we define $Q^{\prime \prime}=\left[\mathbf{q}^{M S}, \mathbf{q}^{E S}\right]$ where $\mathbf{q}^{M P}$ and $\mathbf{q}^{W S}$ are the two orthonormale vectors associated to the monetary and exchange rate shock. This implies that the two vectors of our $A^{\prime \prime}$

\footnotetext{
${ }^{12}$ For our reduced form coefficients, a flat prior prior is used.
} 
matrix can be written as

$$
\mathbf{a}^{M P}=A^{\text {chol }} \mathbf{q}^{M S} \text { and } \mathbf{a}^{E S}=A^{\text {chol }} \mathbf{q}^{W S}
$$

To find our candidate draws, draws to the $\mathbf{q}^{M P}$ and $\mathbf{q}^{E S}$ vectors must be made. To accomplish this, we adopt the following two step procedure. For the first step, the following vector of numerical draws are made:

$$
\mathbf{v}^{M P} \sim \text { i.i.d.N }\left(0, \operatorname{diag}\left(\sigma^{M P}\right)\right) \text { and } \mathbf{v}^{E S} \sim i . i . d . N\left(0, \operatorname{diag}\left(\sigma^{E S}\right)\right)
$$

Where we have that $\sigma^{M S}=(0,0,0,1, \ldots, 1)$ and $\sigma^{E S}=(0,0,1,1 \ldots, 1)$ for $A_{\text {default }}^{\prime \prime}$ and $A_{\text {robust }_{I}}^{\prime \prime}$ while $\sigma^{E S}=(0,0,0,1 \ldots, 1)$ in $A_{\text {robust }}^{\prime \prime}{ }{ }^{13}$ In the second step, the vector of numerical draws are used as input to determine $\mathbf{q}^{M S}$ and $\mathbf{q}^{E S}$. To preserve the mutually perpendicular and orthonormality properties for these two vectors we adopt the GramSchmidt procedure: ${ }^{14}$

$$
\begin{aligned}
& \mathbf{u}^{M S}=\mathbf{v}^{M S} \\
& \mathbf{u}^{E S}=\mathbf{v}^{E S}-\operatorname{proj}_{\mathbf{u}^{M S}}\left(\mathbf{v}^{E S}\right)
\end{aligned}
$$

$$
\begin{aligned}
& \mathbf{q}^{M S}=\frac{\mathbf{u}^{M S}}{\left\|\mathbf{u}^{M S}\right\|} \\
& \mathbf{q}^{E S}=\frac{\mathbf{u}^{E S}}{\left\|\mathbf{u}^{E S}\right\|}
\end{aligned}
$$

By repeating the two steps above $n 2$ times determines all the candidate draws for $\mathbf{a}^{M S}$ and $\mathbf{a}^{E S}$ needed to implement the second part of our numerical procedure.

\footnotetext{
${ }^{13}$ The zero elements here map zero restrictions into our $A^{\prime \prime}$ matrix.

${ }^{14}$ The projection operator used here is defined as $\operatorname{proj}_{\mathbf{u}^{k}}\left(\mathbf{v}^{k}\right) \equiv \frac{<\mathbf{u}^{k}, \mathbf{v}^{k}>}{\left\langle\mathbf{v}^{k}, \mathbf{v}^{k}>\right.} \mathbf{u}^{k}$.
} 


\section{Appendix B: Additional Figures}

\subsection{Additional figures - Robustness}

Figure 7: Australia: The response to monetary policy shocks and exchange rate shocks

(Robustness I)

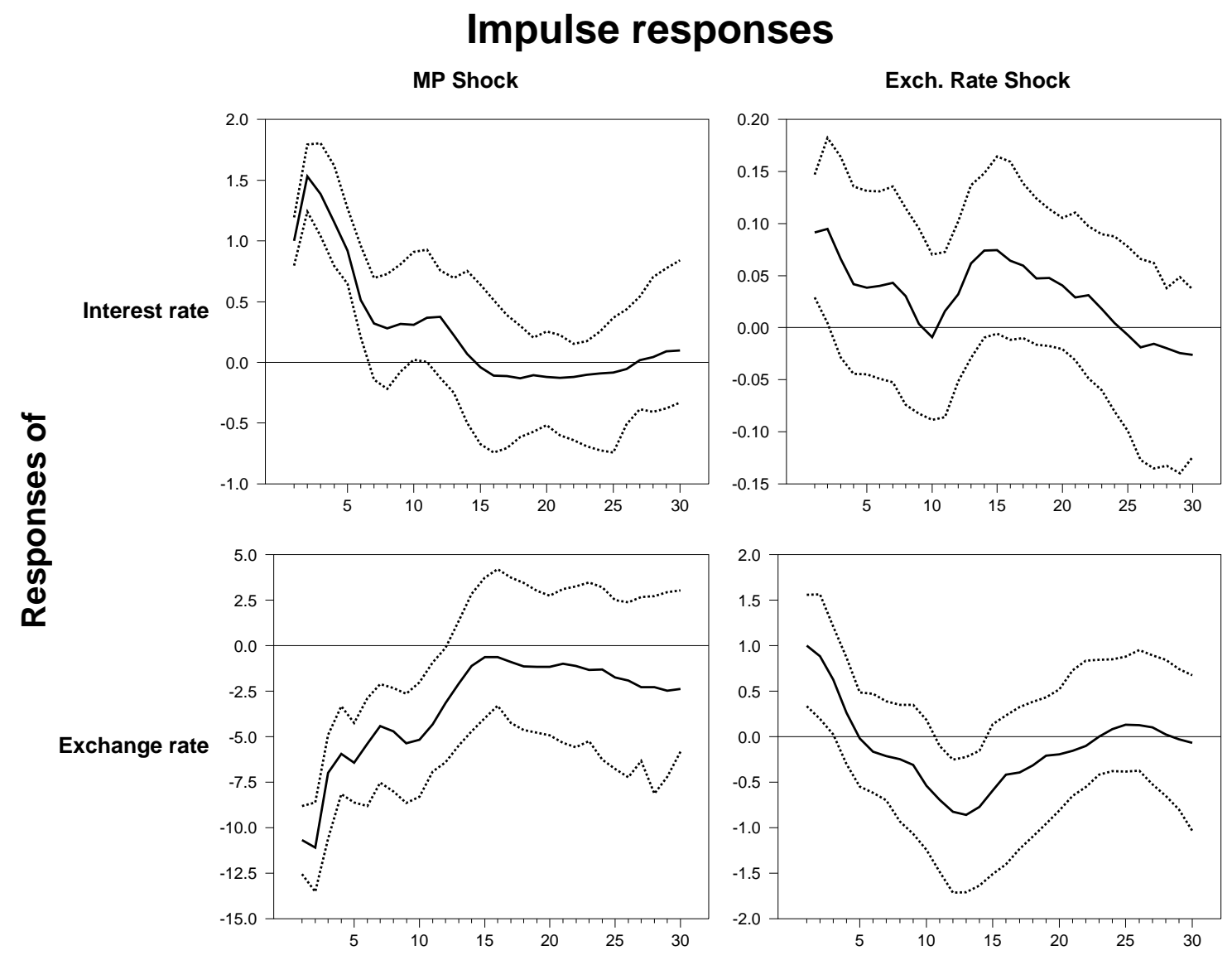


Figure 8: Canada: The response to monetary policy shocks and exchange rate shocks (Robustness I)

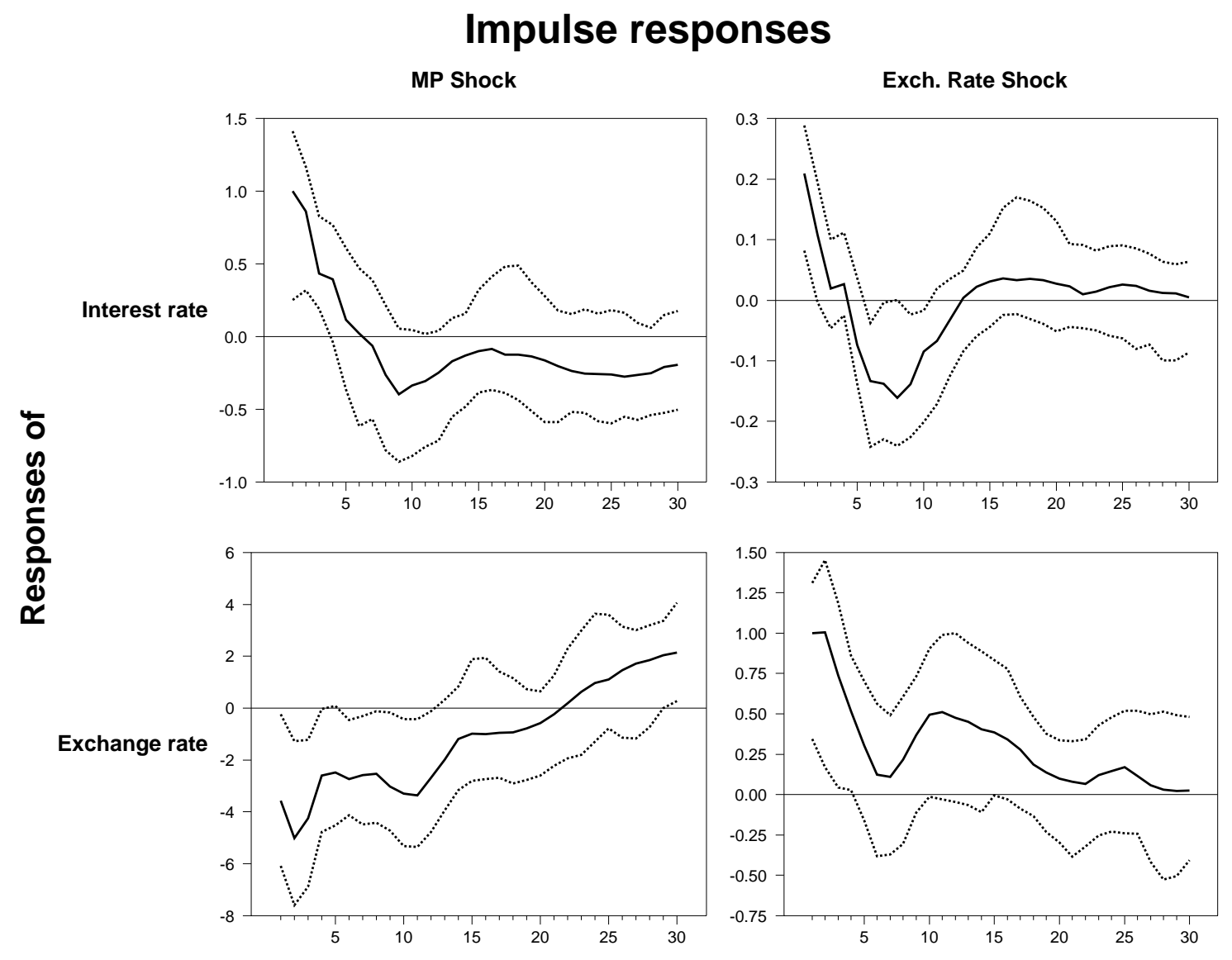


Figure 9: New Zealand: The response to monetary policy shocks and exchange rate shocks (Robustness I)
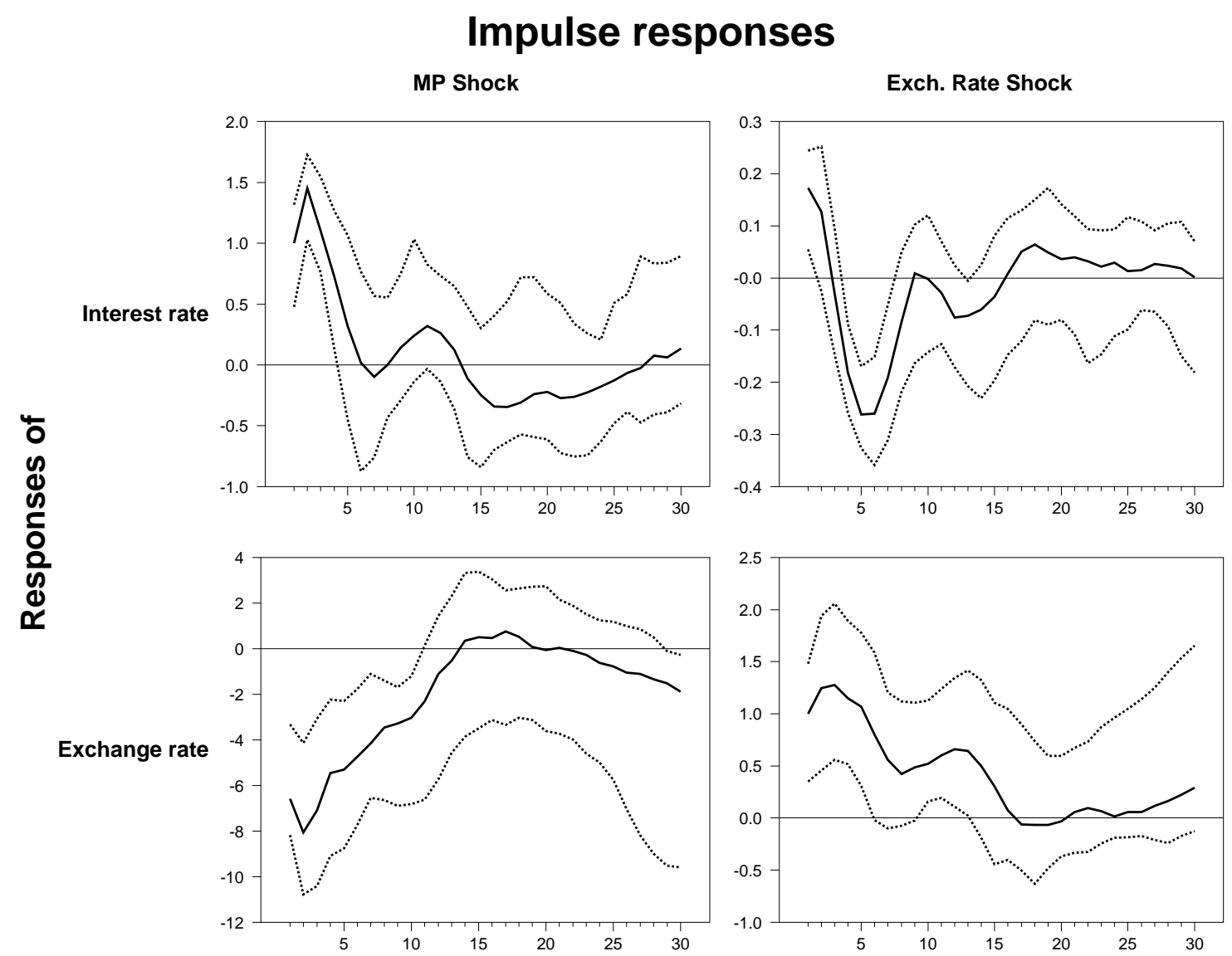
Figure 10: Norway: The response to monetary policy shocks and exchange rate shocks (Robustness I)
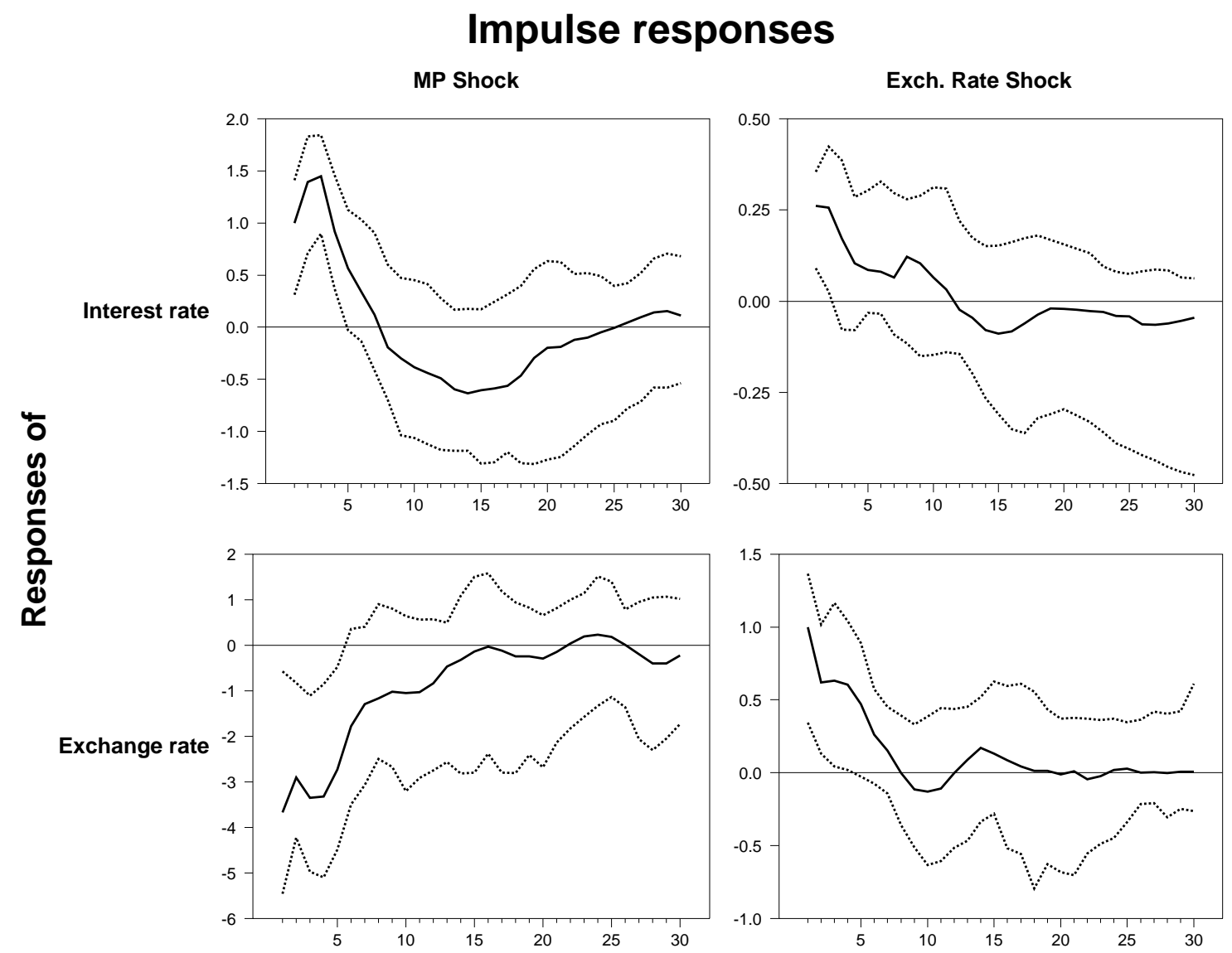
Figure 11: Sweden: The response to monetary policy shocks and exchange rate shocks (Robustness I)

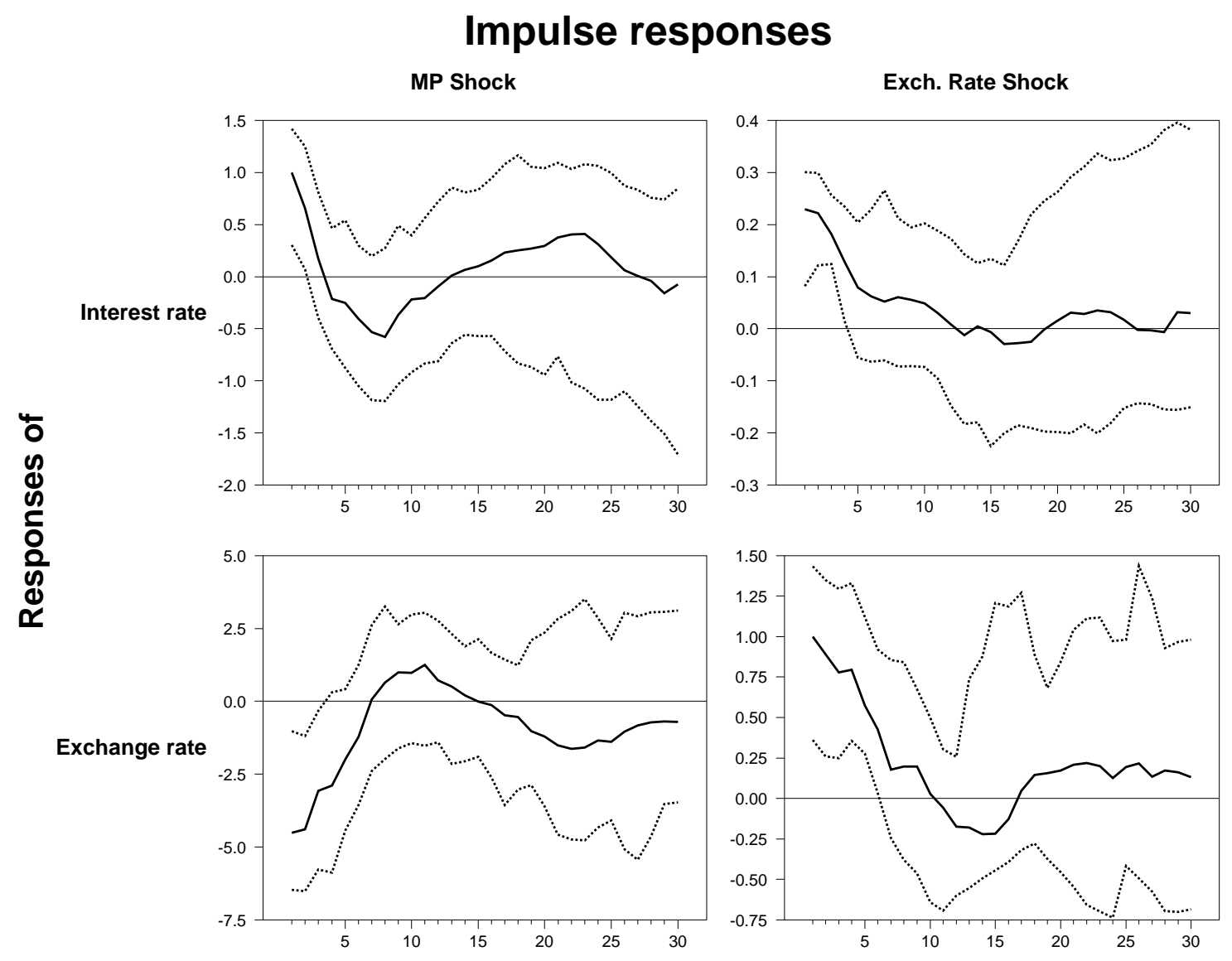


Figure 12: UK: The response to monetary policy shocks and exchange rate shocks (Robustness I)
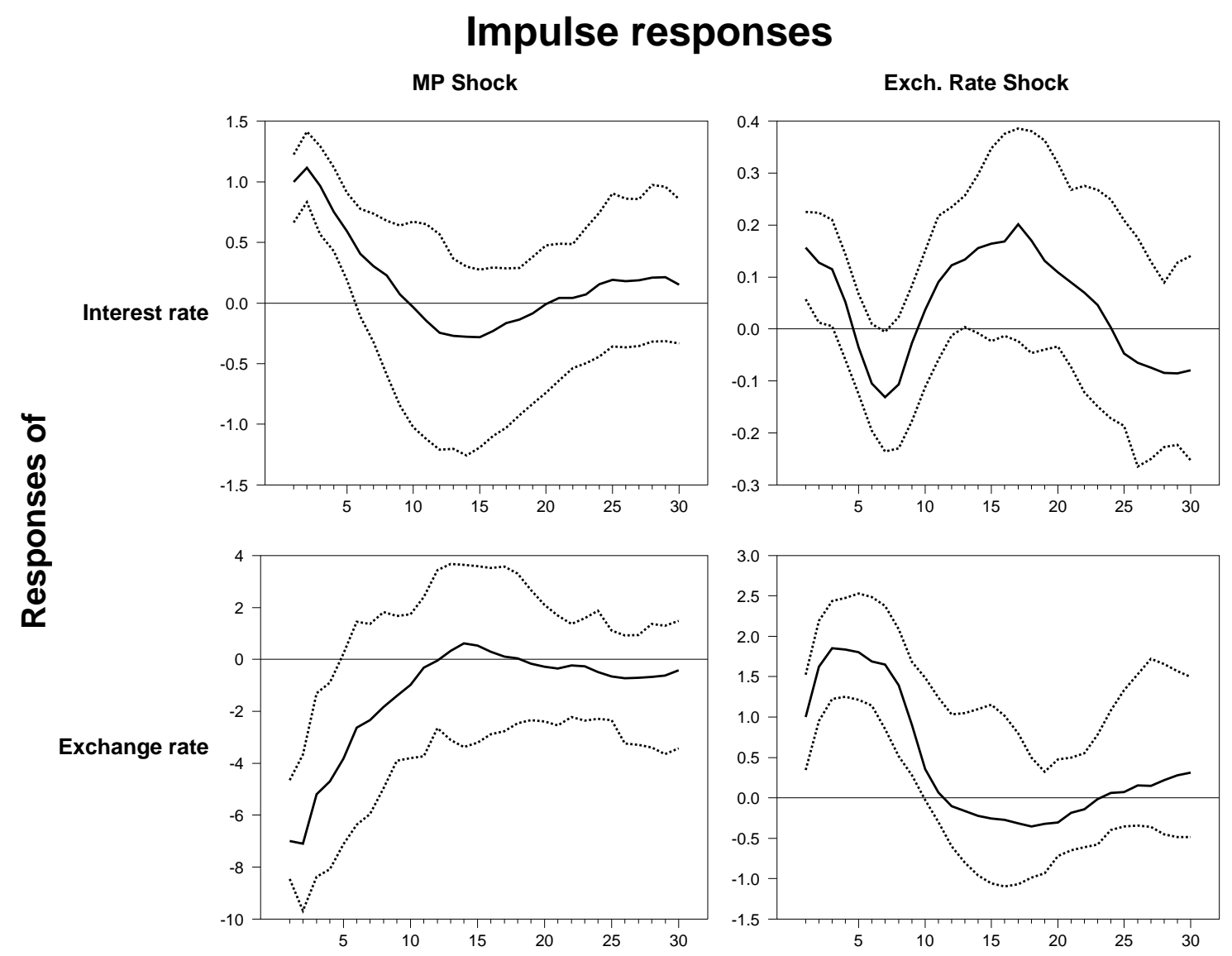
Figure 13: Australia: The response to monetary policy shocks and exchange rate shocks (Robustness II)

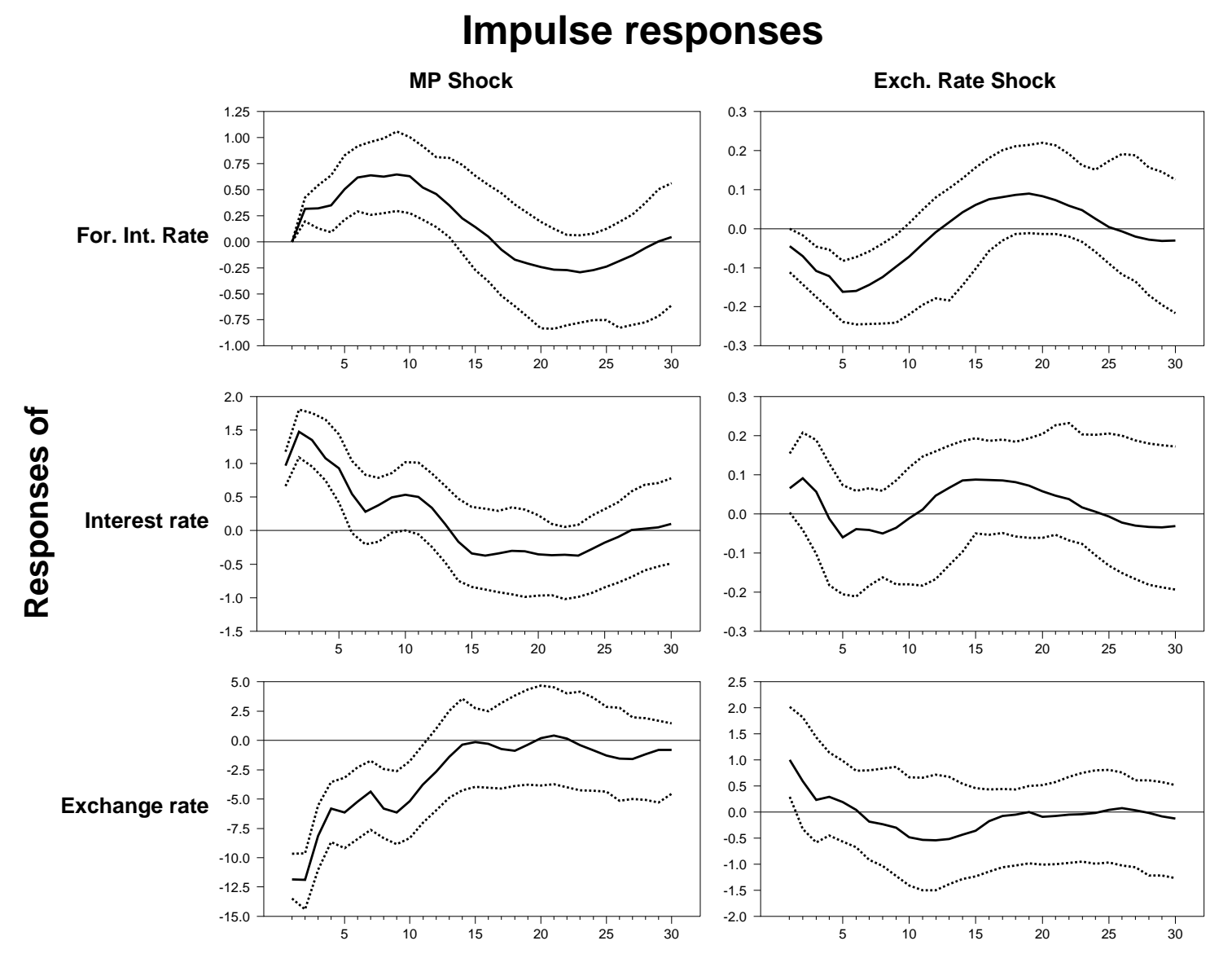


Figure 14: New Zealand: The response to monetary policy shocks and exchange rate shocks (Robustness II)

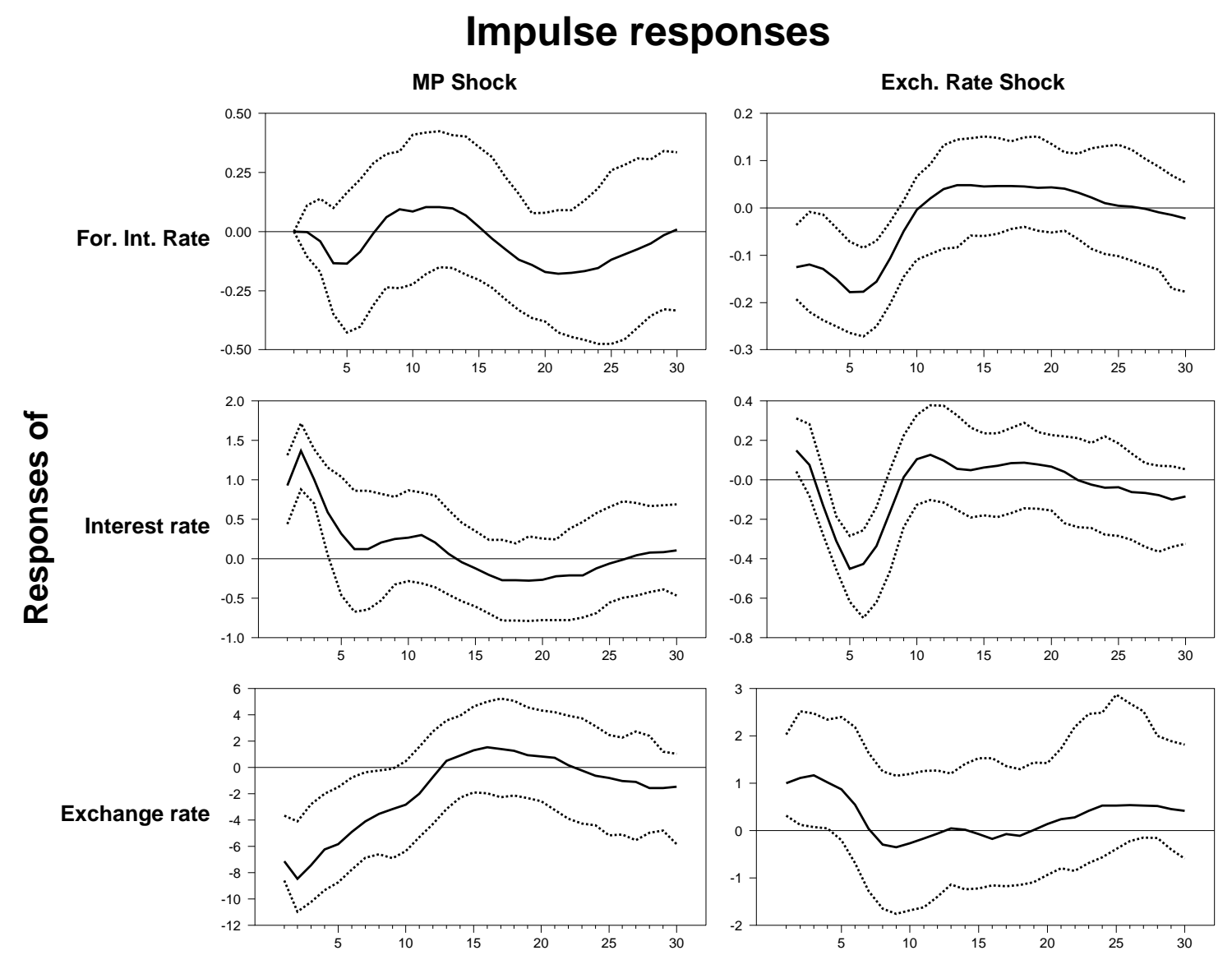


Figure 15: Norway: The response to monetary policy shocks and exchange rate shocks (Robustness II)

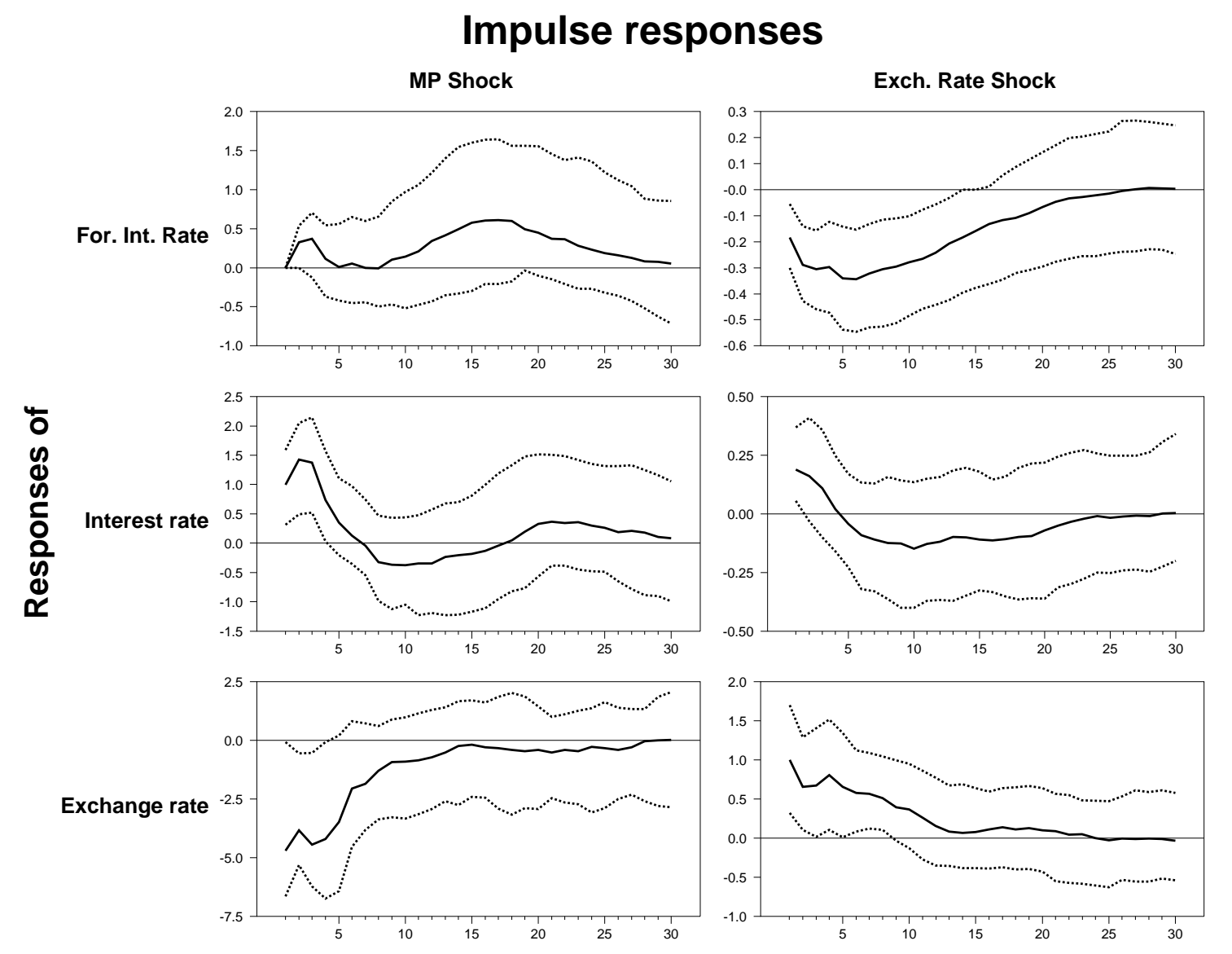


Figure 16: Sweden: The response to monetary policy shocks and exchange rate shocks (Robustness II)

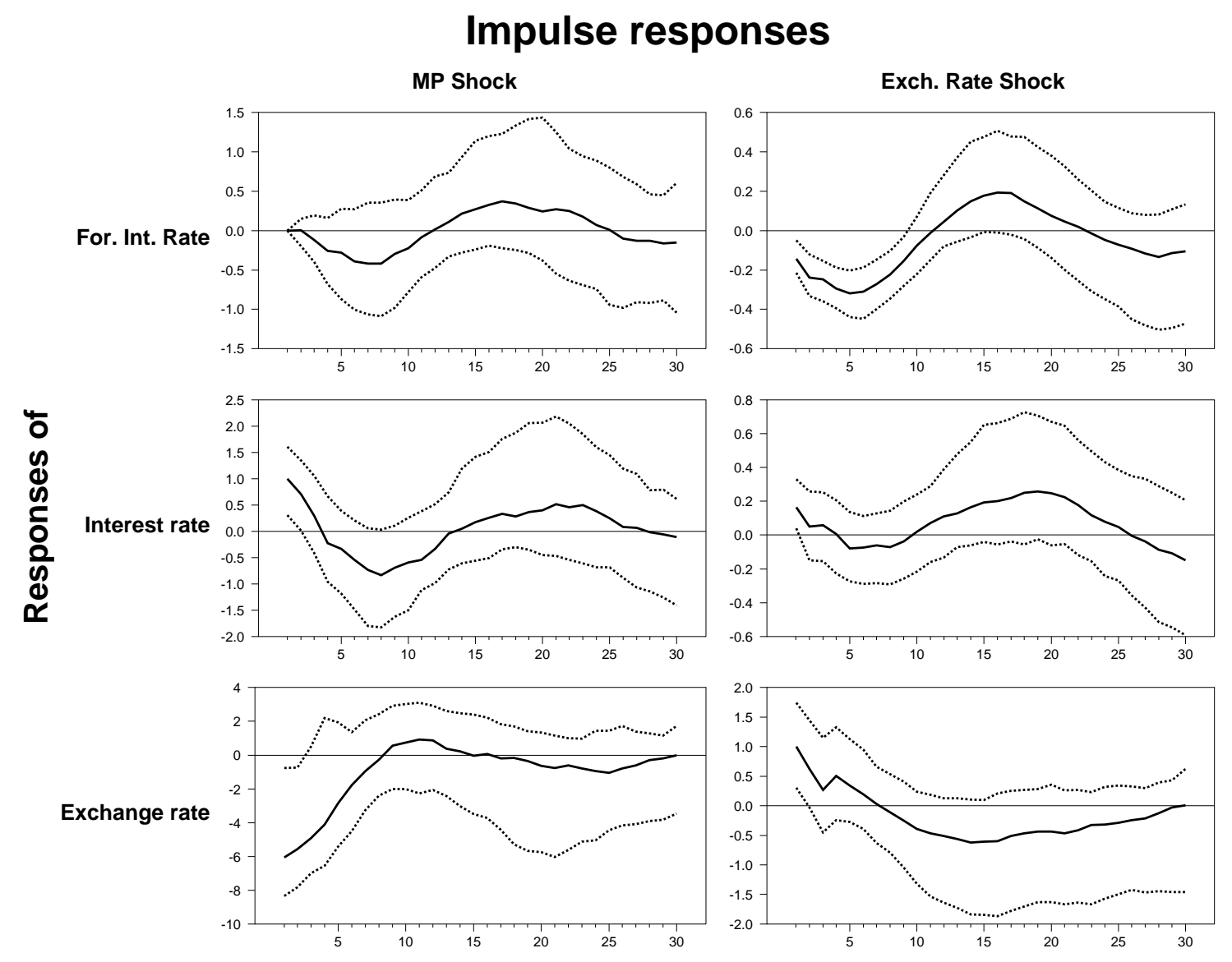




\subsection{Additional Figures - Cholesky}

Figure 17: Australia: The response to monetary policy shocks and exchange rate shocks; Cholesky (solid line) versus sign restrictions (dotted line)

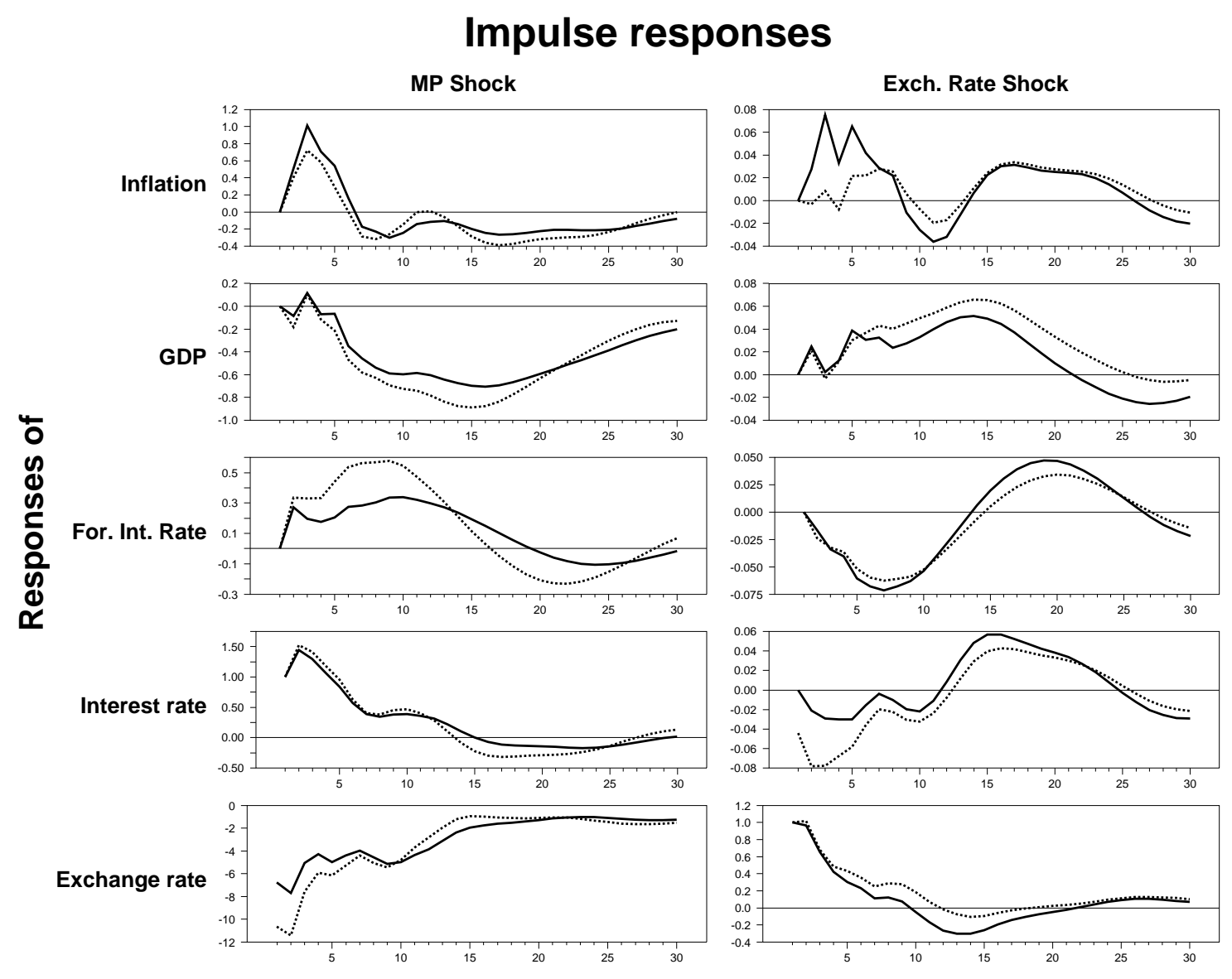


Figure 18: Canada: The response to monetary policy shocks and exchange rate shocks; Cholesky (solid line) versus sign restrictions (dotted line)

\section{Impulse responses}
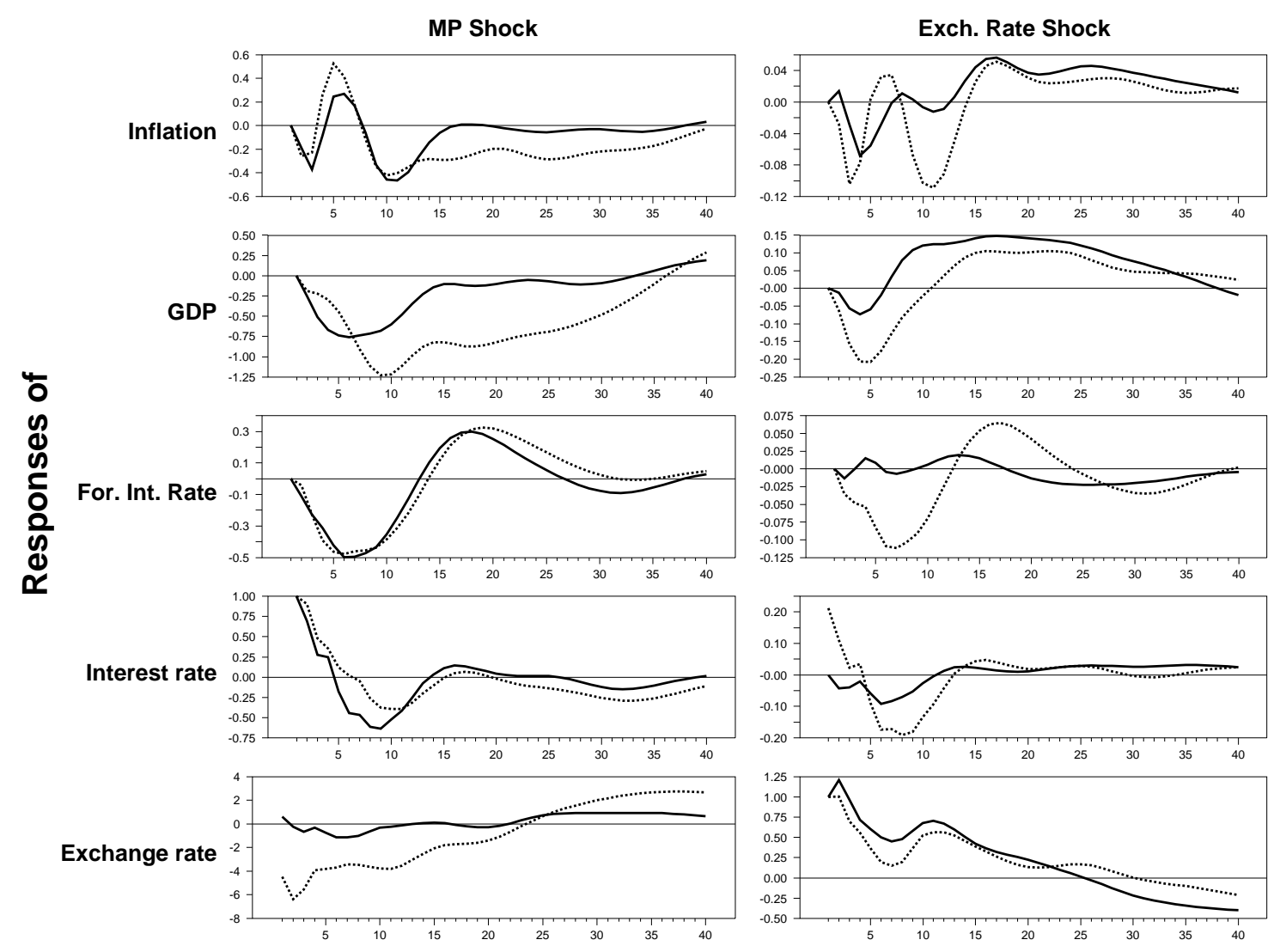
Figure 19: Norway: The response to monetary policy shocks and exchange rate shocks; Cholesky (solid line) versus sign restrictions (dotted line)

\section{Impulse responses}

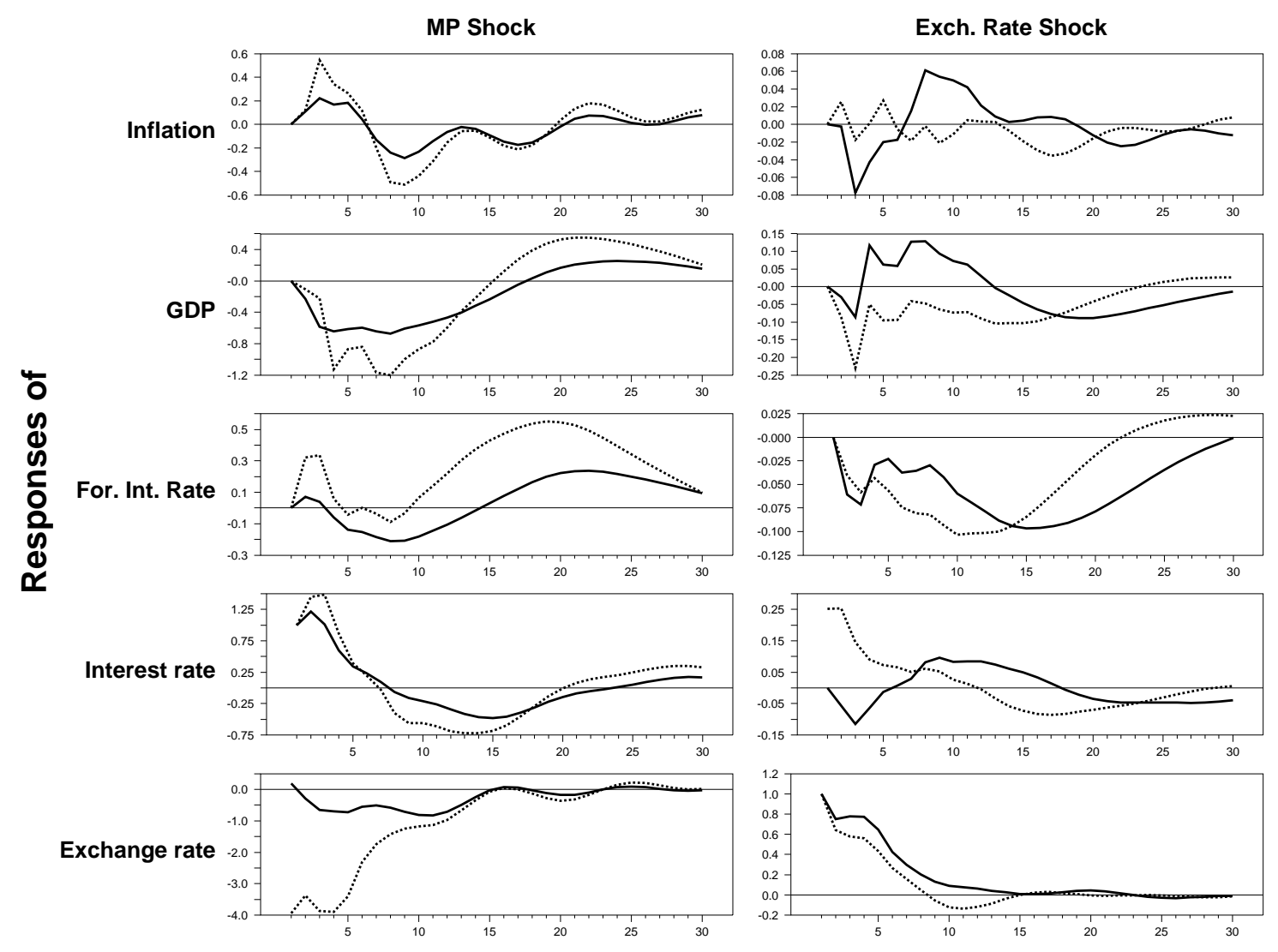


Figure 20: New Zealand: The response to monetary policy shocks and exchange rate shocks; Cholesky (solid line) versus sign restrictions (dotted line)

\section{Impulse responses}

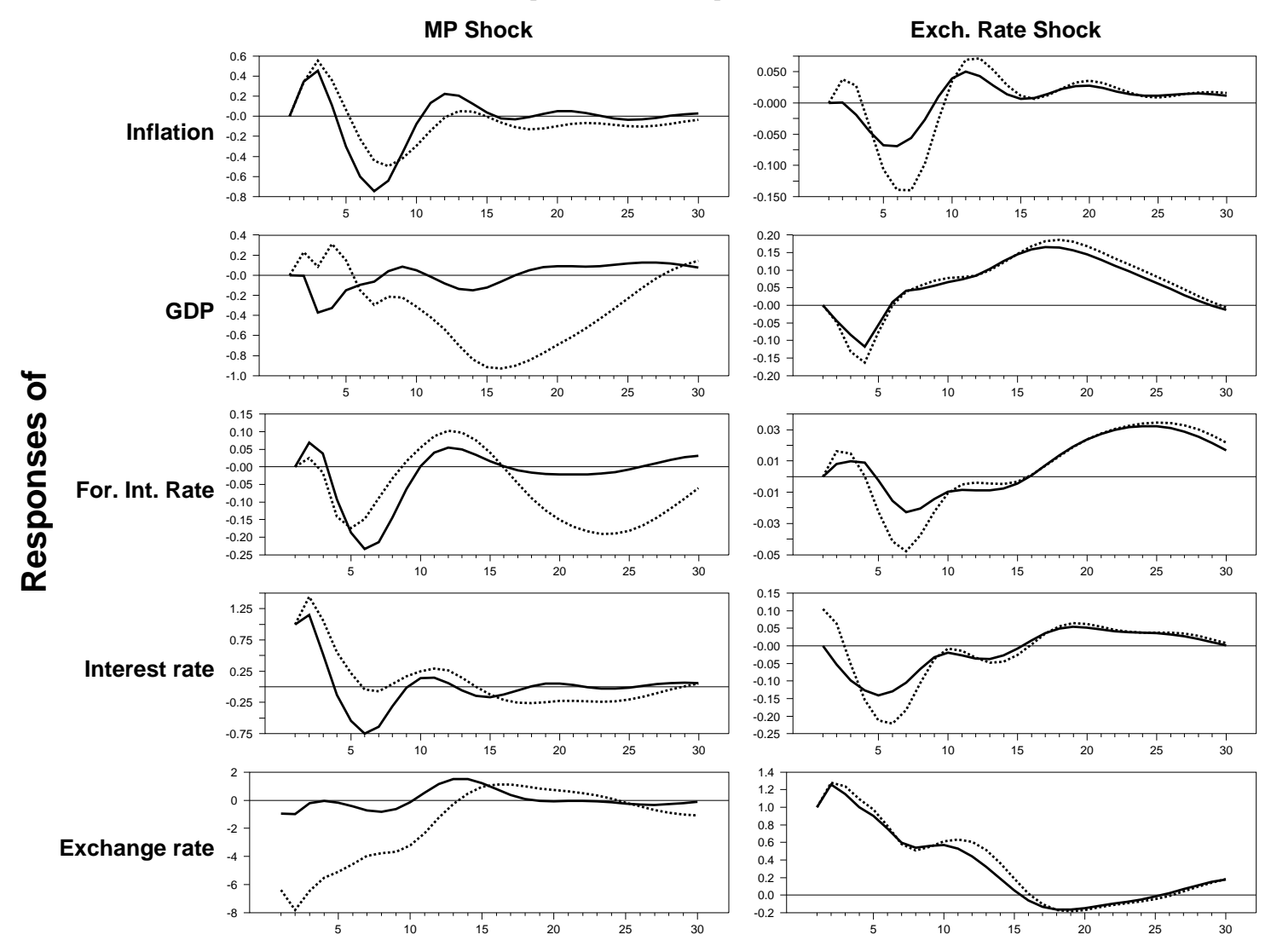


Figure 21: Sweden: The response to monetary policy shocks and exchange rate shocks; Cholesky (solid line) versus sign restrictions (dotted line)

\section{Impulse responses}

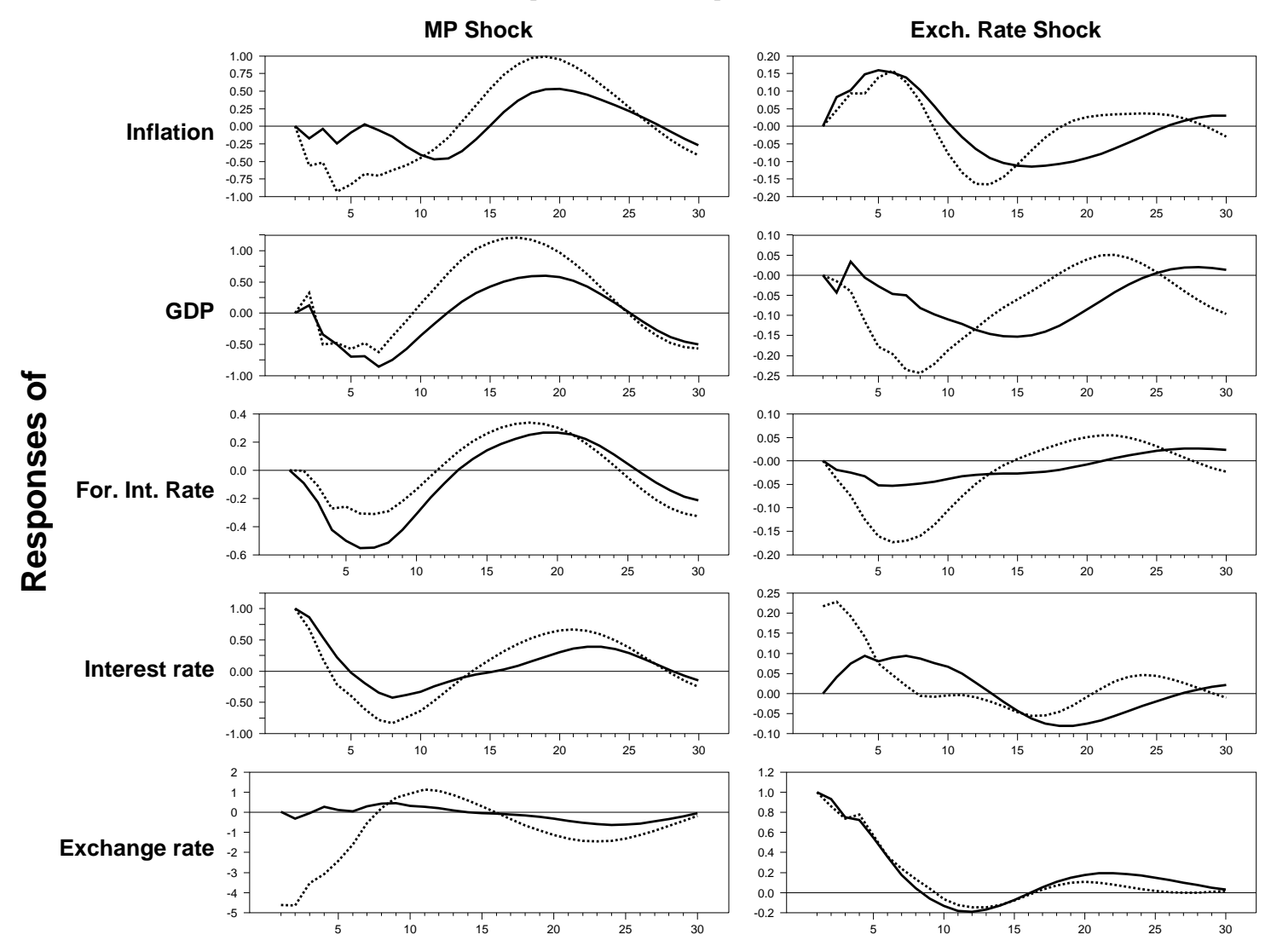


Figure 22: UK: The response to monetary policy shocks and exchange rate shocks; Cholesky (solid line) versus sign restrictions (dotted line)

\section{Impulse responses}
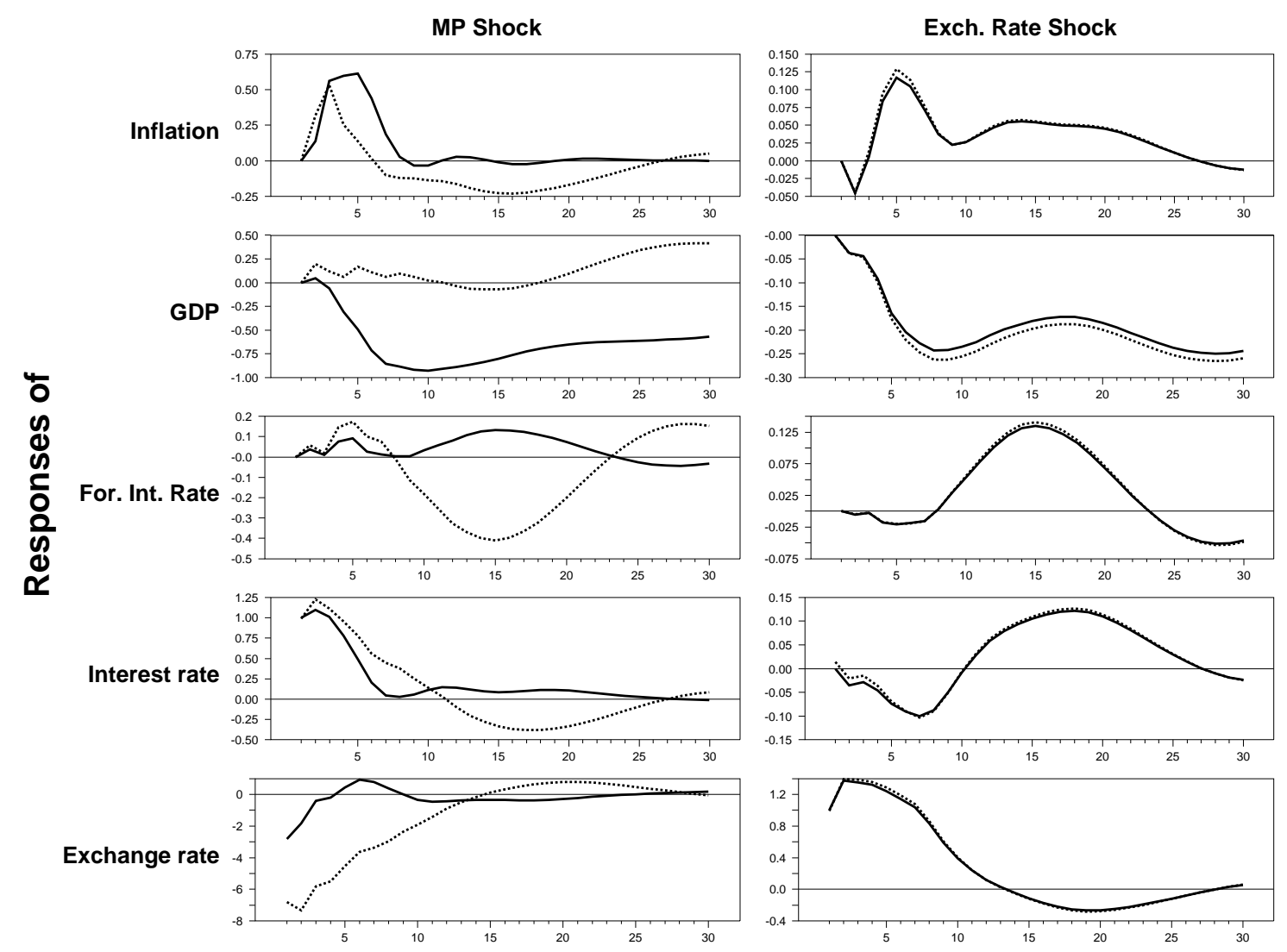


\section{Centre for Applied Macroeconomic Research (CAMAR)}

The objective of CAMAR is to provide high quality research and analysis into the field of macroeconomics, as well as financial issues.

The research activities of CAMAR will be broad and will encompass all elements pertaining to the analysis of macroeconomic data.

BI Norwegian School of Management Centre for Applied Macroeconomic Research (CAMAR) N-0442 Oslo

http://www.bi.no/camar 